\title{
Autoignition behavior of gasoline/ethanol blends at engine-relevant conditions
}

Song Cheng ${ }^{1}$, Dongil Kang ${ }^{1}$, Aleksandr Fridlyand ${ }^{1}$, S. Scott Goldsborough ${ }^{1 *}$, Chiara Saggese ${ }^{2}$,

Scott Wagnon², Matthew J. McNenly², Marco Mehl², William J. Pitz² and David Vuilleumier ${ }^{3}$

${ }^{1}$ Energy System Division, Argonne National Laboratory

9700 S. Cass Avenue, Argonne, IL 60439, USA

${ }^{2}$ Materials Science Division, Lawrence Livermore National Laboratory

7000 East Avenue, Livermore, CA, 94551, USA

${ }^{3}$ Department of Mechanical Engineering, University of California at Berkeley

6141 Etcheverry Hall, Berkeley, CA 94720-1740, USA

${ }^{*}$ Corresponding Author:

S. Scott Goldsborough

Argonne National Laboratory

9700 S. Cass Avenue

Argonne, IL 60439

$+1-630-252-9375$

scott.goldsborough@anl.gov 


\section{ABSTRACT}

Ethanol is an attractive oxygenate increasingly used for blending with petroleum-derived gasoline yielding beneficial combustion and emissions behavior for a range of internal combustion engine schemes, including stoichiometric spark-ignition and low temperature combustion (LTC). As such, it is important to fundamentally understand the autoignition behavior of gasoline/ethanol blends. This work utilizes a rapid compression machine (RCM) and a homogeneous charge compression ignition $(\mathrm{HCCl})$ engine to experimentally quantify changes in fuel reactivity, through ignition delay times and preliminary heat release, for blends of 0 to $30 \%$ vol./vol. into a full boiling range research gasoline (FACE-F). Diluted/stoichiometric and undiluted/fuel-lean conditions are explored covering a wide range of compressed temperatures and pressures relevant to conventional and advanced, gasoline combustion engines. Detailed chemical kinetic modeling is undertaken using a recently updated gasoline surrogate model in conjunction with a five-component surrogate to model the RCM experiments and provide chemical insight into the perturbative effects of ethanol on the autoignition process.

The diluted/stoichiometric RCM measurements reveal that within the low-temperature regime ethanol retards first-stage and main ignition delay times, and suppresses both the rates and extents of low-temperature heat release (LTHR), while within the intermediate-temperature regime ethanol only causes slight changes. Good agreement of ignition delay time and preliminary heat release prediction is found between model and experimental results. Sensitivity and flux analyses further show that ethanol blending effects are dominated by the competition between the $\mathrm{H}$-atom abstraction from ethanol and other fuel components by $\mathrm{OH}$ radical at low temperatures and by $\mathrm{HO}_{2}$ radical at intermediate temperatures. These findings are consistent 
across both fuel loading conditions explored in this study. In addition, when $\mathrm{HCCl}$ engine experiments are mapped onto undiluted/lean RCM measurements under a constant combustion phasing scenario, good correspondence between the two apparatuses is observed for LTHR and start of high-temperature heat release. The current study highlights the importance of characterizing LTHR in predicting fuel behaviors in high-boost/low-temperature engines, and demonstrates that RCM experiments can provide an alternative, and more-efficient avenue for such characterization.

Keywords: autoignition, gasoline/ethanol blends, preliminary heat release, chemical kinetic modeling. 


\section{INTRODUCTION}

Ethanol addition to petroleum-derived gasoline can facilitate knock resistance [1] in spark-ignition (SI) engines, allowing higher compression ratios and boosted intake pressure that enable higher engine efficiency. Ethanol-blended gasoline also reduces regulated emissions, in particular $\mathrm{NO}_{x}$ [2], carbon monoxide (CO) and particulate matter (PM) [3]. As such, ethanol remains an attractive and dominant biofuel for transportation use. Although currently blended at $10 \%$ by volume in U.S. E10 gasoline, recent energy policies, such as RFS2 [4], seek to increase ethanol use in transportation fuels.

In concert with these efforts, engineers have attempted to meet stringent emission regulations and fuel economy targets by exploring advanced combustion concepts such as Low Temperature Combustion (LTC). LTC can be achieved at diluted or lean fuel loading conditions at thermodynamic conditions where the fuel autoignition behavior is significantly affected by its low-temperature chemistry [5]. When boosted pressure is used to increase power density, the enhancement of low-temperature chemistry can lead to advanced combustion phasing, which can, in turn, develop into abnormal combustion events $[6,7]$ resulting in significant engine noise and harsh operation. These abnormal behaviors stem in large part from the complex and sensitive chemistry at LTC engine conditions. A thorough understanding of low-temperature autoignition chemistry, and the influence of ethanol blending is hence critical towards mitigating controlling difficulties, as well as providing groundwork required for designing and enabling advanced combustion engines.

Understanding low- and intermediate-temperature autoignition chemistry of gasoline/ethanol blends can be challenging as ethanol can perturb the base gasoline chemistry 
in various ways. First, the reaction pathways of ethanol oxidation differ from those of typical, petroleum-derived gasoline constituents. For instance, it has been reported that ethanol favors $\mathrm{OH}$ radical scavenging pathways forming acetaldehyde and hydroperoxyl radicals over conventional low-temperature chain branching pathways [8-10]. Second, ethanol has been observed to show synergistic blending effects on octane number with $n$ - and iso-paraffins [11], while antagonistic blending effects with aromatics [12]. Furthermore, ethanol has a high latent heat of vaporization which reduces charge temperatures in direct and port fuel injection engines, impacting the oxidation pathways of the blends leading to autoignition [2]. These kinetic and physical properties lead to different blending interactions with different hydrocarbon structures. Although it has been recently found that computational singular perturbation can be utilized to enable systematic analysis of the specific reactions responsible for autoignition suppression with ethanol addition [13], the autoignition chemistry behind various blending effects is still not well understood.

Base gasolines used in historical blending studies vary in composition due to different sources of crude oil. As such, contradictory blending effects have been observed in the past (e.g., synergistic response with U.S. gasolines [14] and an antagonistic blending effects with an Australian gasoline [1]). Such inconsistencies make quantitative comparison among data acquired by different laboratories difficult. To facilitate more insightful investigations, standardized formulations, such as the Fuels for Advanced Combustion Engines (FACE) developed by the Coordinating Research Council [15], could be used.

Fundamental autoignition studies with FACE gasoline/ethanol blends are scarce, though some can be found for other oxygenated gasolines with ethanol $[16,17]$. To date, ethanol 
influence on combustion characteristics of FACE gasolines have been investigated under Homogeneous Charge Compression Ignition ( $\mathrm{HCCI})[11,18-21]$, Spark-Ignition $(\mathrm{SI})[18,19]$ and Advanced Compression Ignition (ACl) $[18,19]$ combustion modes, as well as in Rapid Compression Machines (RCMs) [21]. Most experiments have mainly focused on engine apparatuses where chemical kinetics are implicitly coupled with non-negligible physical phenomena such as interplays with thermal/compositional non-uniformities, turbulent flame propagation and gas dynamics, making systematic and accurate evaluation of low- and intermediate-temperature chemistry challenging. Homogeneous, gas-phase autoignition measurements at engine-relevant thermodynamic conditions in RCMs and shock tubes are thus important [22]. Only one such study [21] is available however, and it is limited to using simple gasolines (FACE-A and FACE-C) with minor octane sensitivity (0.1 and 1.1, respectively [15]). Studying octane-sensitive gasolines is of particular interest though, as commercial gasoline is commonly octane-sensitive (the arithmetic difference between the Research and Motor Octane methods $[23,24])$ due to the presence of substantial aromatics and olefins. Furthermore, fuel octane sensitivity is an important fuel property for many combustion schemes, as it has been found to correlate with Negative Temperature Coefficient (NTC) behavior, which is a key feature in low-temperature autoignition [25] and links low temperature heat release (LTHR) to intermediate-temperature heat release (ITHR) in typical two-stage ignition [26]. Ethanol, on the contrary, has been confirmed to not exhibit NTC, or low-temperature autoignition behavior [27, 28], which is in line with its high octane sensitivity. Finally, flux and sensitivity analyses, such as reported in [21], provide valuable insights into the dominant oxidation pathways of gasoline surrogate/ethanol blends. But, these have only been conducted for two-component primary 
reference fuels (PRF, $n$-heptane and iso-octane), whereas investigations are needed for multicomponent gasoline surrogate/ethanol blends that are representative of full boiling range gasolines. Comprehensive experimental investigations at engine-representative conditions using octane sensitive FACE gasoline/ethanol blends in well-controlled apparatuses, such as RCMs, are significantly needed.

To address these needs, new experimental measurements are conducted for FACEF/ethanol blends in an RCM and an $\mathrm{HCCl}$ engine. FACE- $\mathrm{F}$ is selected as it has a $\mathrm{C} / \mathrm{H}$ ratio and octane sensitivity representative of many commercial gasolines [15]. The effects of ethanol addition are studied by adding $10 \%, 20 \%$ and $30 \%$ ethanol by volume into the base gasoline. 'Neat' FACE-F and 'neat' ethanol are also used as reference fuels. Two fuel loading conditions are used, one that represents diluted/boosted SI engine operation and another representing undiluted/lean $\mathrm{ACl}$ operation, covering a range of engine relevant conditions with pressures from 15 to 80 bar and temperatures from 700 to $1000 \mathrm{~K}$. To quantify fuel reactivity, sweeps of inlet pressure and temperature are used in the $\mathrm{HCCl}$ engine where combustion phasing is held constant, allowing comparisons with published work [21]. Changes to overall reactivity and extents of LTHR/ITHR are quantified. A recently-updated, multi-component gasoline surrogate model from Lawrence Livermore National Laboratory (LLNL) [29] is also used to model the RCM experiments and perform flux and sensitivity analyses to assist fundamental interpretation of the dominant chemistry and key pathways at the selected conditions.

The remaining manuscript is organized as follows. Section 2 provides a description of the two experimental facilitates used for data acquisition as well as the methods used for postprocessing and kinetic modeling in this study. Section 3 discusses the experimental and modeling 
results at the two fuel loading conditions. Sensitivity and flux analyses results are then presented and discussed in that section. This is followed by a summary of the paper in Section 4.

\section{EXPERIMENTAL AND COMPUTATIONAL METHOD}

\subsection{Rapid compression machine}

\subsubsection{Description}

A heated, twin-piston RCM (tpRCM) at Argonne National Laboratory (ANL) is utilized for this study. A detailed description of the configuration as well as uncertainties associated with experimental measurements can be found in [30], and are also briefly described herein. A single compression event is driven by the pneumatic system and a hydraulic pin-groove arrangement is used to arrest the fast-moving pistons, allowing them to be hydraulically locked at the end of compression. The time for compression ( $\left.t_{\text {comp }}\right)$ and last $50 \%$ of pressure rise $\left(t_{50}\right)$, are approximately 15-18 ms and 1.9-2.0 ms, respectively, depending on the compressed pressure $\left(P_{C}\right)$.

The reaction chamber, with an inner diameter of $50.8 \mathrm{~mm}$, is located between the two compression cylinders, while the clearance height at the end of compression is nominally 25.5 $\mathrm{mm}$. The geometric compression ratio (CR) is 12.1:1; however, the effective compression ratio, when taking into account the heat loss during the compression, ranges from 11.2:1 to $11.8: 1$ depending on compressed state conditions, primarily Pc, and diluent conditions. The stroke for each reaction chamber piston is approximately $155.8 \mathrm{~mm}$. The pistons utilize crevices machined around their circumference [30] to suppress possible vortex roll-up during the compression, thus improving post-compression charge homogeneity. The dynamic pressure in the reaction 
chamber is measured using a flush-mounted Kistler 6045A-U20 pressure transducer calibrated to 250 bar, and coupled to a Kistler Type 5064 charge amplifier. The transducer has a reinforced diaphragm for applications at excessive pressure rise rates. The thermal shock error of the transducer is estimated at $\Delta \mathrm{P}_{\max }< \pm 1 \%$.

To accurately capture two-stage exothermic characteristics, the pressure signal can be split and recorded using two different National Instruments (NI) data acquisition cards. Since the firststage heat release features much lower heat release rates, a 24-bit card is used for this study (NI 9239), sampled at $50 \mathrm{kHz}$. Higher rates of heat release, e.g., through the high temperature heat release (HTHR) process, are more robustly captured with a 16-bit card (NI 9223) sampled at 1 MHz. Goldsborough et al. [31] identify DAQ and post-processing issues associated with heat release rate calculations. The pressure signal is filtered using the Savitzky-Golay algorithm with a second-order polynomial fit over a window of $0.2 \mathrm{~ms}$ (i.e., 11-point window for the $50 \mathrm{kHZ}$ data and 201-point window for the $1 \mathrm{MHz}$ data).

\subsubsection{Mixture preparation}

A $5.6 \mathrm{~L}$, stainless steel tank is heated to $\sim 70{ }^{\circ} \mathrm{C}$ and is used to prepare mixtures of fuel, diluents ( $\mathrm{Ar}$ and $\mathrm{N}_{2}$ ), and $\mathrm{O}_{2}$. The mixing tank is initially purged with inert gas and evacuated to at least 0.1 mbar using an Edwards nXDS6i vacuum pump. A pre-determined mass of liquid fuel is first introduced into the tank through a septum, and then high-purity gases are supplied into the tank in the sequence of $\operatorname{Ar}$ (99.9997\%, Airgas), $\mathrm{N}_{2}$ (99.9998\%, Airgas) and $\mathrm{O}_{2}$ (99.9997\%, Airgas). The manual filling valves placed upstream of the mixing tank inlet allow gases to be metered to within 3 mbar of the desired value. Each feed requires an interval waiting time of $3-5$ minutes to 
equilibrate the pressure of the tank, which is monitored using an MKS Baratron 628F (0-6666 mbar) heated manometer with a manufacturer specified uncertainty of $0.25 \%$. After completion of each mixture preparation, the mixture in the tank is isolated for 45 minutes to diffusively mix. The evaporation efficiency of each test fuel is calculated based on ideal gas relations and is $>95 \%$, while the molar composition of the mixture is estimated from the partial pressure of gaseous components and the mass of fuel injected.

\subsubsection{Experimental procedure}

The surfaces of the reaction chamber and cylinders are heated using electrical heating tapes to the desired temperature adjusted according to the initial condition of test. The K-type thermocouples are placed at 16 different positions along the cylinder and chamber surfaces to periodically monitor the surface temperatures. Once the temperatures reach the target condition, the condition is maintained constant for $30-45$ minutes prior to firing the tpRCM in order to ensure the uniformity of interior wall temperatures. The reaction chamber is evacuated and purged several times using dry, bottled air (99.998\% purify Airgas) before each filling event. Afterwards, the test mixture is manually metered into the reaction chamber to the targeted initial pressure through PTFE-lined and stainless-steel tubing heated to approximately $70{ }^{\circ} \mathrm{C}$. The reaction chamber pressure is measured using an Omegadyne PX01C1-050AI (0-3446 mbar) pressure transducer with the maximum manufacturer specified uncertainty as $\pm 3 \%$. The test mixture is allowed to equilibrate for at least 5 minutes in the chamber before commencing the test. At each compressed state, a minimum of two shots are conducted to ensure repeatability. 


\subsubsection{Data Analysis Processing}

The compressed temperature $(\mathrm{Tc})$, ignition delay times and heat release rates are determined by post-processing recorded pressure traces. In order to ascertain the end of compression ( $\left.t_{0}\right)$ and the extent of the heat loss during ignition delay period, a non-reactive test, wherein $\mathrm{O}_{2}$ in the test mixture is replaced with $\mathrm{N}_{2}$, is conducted for each reactive case.

The compressed temperatures are calculated using the adiabatic core hypothesis,

$$
\int_{T_{i}}^{T_{C}} \frac{\gamma}{\gamma-1} \frac{d T}{T}=\ln \frac{P_{c}}{P_{i}}
$$

where the subscripts ' $i$ ' and ' $c$ ' indicate initial and compressed conditions, while $\gamma$ is the ratio of specific heat of the gas mixture. The ideal gas law is applied over all of the experimental conditions including pre- and post-compression, and the specific heat of the gas is taken to be a function of the initial mixture composition as well as the individual specific heat of the gas constituents. The specific heat of each gas constituent is estimated from polynomial fits of published data, which are functions of temperature.

An energy balance approach [32] is used to calculate the heat release rates (HRR), and accumulated, or integrated heat release. The volumetric compression, and the accompanying heat loss and crevice flow processes are also incorporated into the analysis with the measured non-reacting pressure traces. This can be expressed as,

$$
H R R=\frac{\gamma}{\gamma-1} \frac{d V}{d t}\left[P-P_{n r}\right]+\frac{1}{\gamma-1} V\left[\frac{d P}{d t}-\left.\frac{d P}{d t}\right|_{n r}\right]-\frac{p V}{(\gamma-1)^{2}}\left[\frac{d \gamma}{d t}-\left.\frac{d \gamma}{d t}\right|_{n r}\right]
$$

where the subscript ' $n r$ ' indicates non-reacting condition. The gas temperature during the reactive tests is calculated using:

$$
T \approx T_{n r}+x_{b}\left(L H V_{m i x} / c_{v}\right)
$$


where $L H V_{\text {mix }}$ is the lower heating value of the mixture, $c_{v}$ is the constant-volume specific heat of the mixture, and $x_{b}$ is the fraction of fuel energy released, which can be deduced from $\int(H R R) d t / L H V_{\text {mix }}$

Figure 1. Representative experimental non-reacting and reacting pressure-time histories of FACE-F/EO (Mix 1) at $\mathrm{PC}=23 \mathrm{bar}, \mathrm{Tc}=752 \mathrm{~K}$ with $\tau_{1}, \tau$, accumulated LTHR and ITHR identified. HRR is normalized by LHV $\mathrm{V}_{\text {mix. }}$

Figure 1 presents two representative reactive traces along with the associated nonreactive trace for a 'neat' FACE-F case (FACE-F/EO), where consistency between the two reactive shots, and alignment between the non-reactive and reactive traces prior to heat release events are excellent. Ignition delay times for first-stage $\left(\tau_{1}\right)$ and main ignition $(\tau)$ are also highlighted in Fig. 1, along with the LTHR and ITHR inferred from the accumulated HRR. The extent of LTHR is calculated as the integrated heat release from $t_{0}$ through the peak HRR at first-stage ignition $\left(\tau_{1}\right)$, up to the inflection point in HRR just before the start of ITHR (solTHR). Similarly, the extent of ITHR is calculated starting from the end of LTHR to the start of high temperature heat release (soHTHR), which are demarcated using definitions from [33] (i.e., $d H R R / d t=0$, and $H R R \sim 0.1 / m s$ for solTHR and soHTHR, respectively). These thresholds are graphically illustrated in Fig. 5 below. Note that all heat release calculations presented in this work are normalized by the LHV of the test mixture, e.g., $(\mathrm{J} / \mathrm{mol} / \mathrm{ms}) /(\mathrm{J} / \mathrm{mol})$.

Uncertainty analyses associated with ANL's tpRCM and the HRR calculations were presented in [30,34], using a similar approach to [35], wherein the uncertainty of measured ignition delay times was estimated as $\pm 0.4 \mathrm{~ms}$, due primarily to improper alignment with the nonreacting traces; statistical (i.e., month-to-month) variability in $\tau$ however, can be on the order of 
$\pm 10 \%$. Uncertainties in Tc are $1.0-1.5 \%$, while those for HRR are $\pm 7.4 \%$, due primarily to the volatility uncertainty of the full boiling range gasoline fuel.

\section{2. $\mathrm{HCCl}$ engine}

\subsubsection{Description}

The $\mathrm{HCCl}$ engine experiments are performed in a 4-cylinder 2.0 liter displacement VW TDI engine located at University of California Berkeley (UCB), which has been modified extensively for $\mathrm{HCCl}$ operation. Only a single cylinder is used and the remaining cylinders are disabled for the current study. The original deep-bowl pistons are replaced with custom shallow-bowl pistons to achieve a higher CR of 16.5:1. Separate intake and exhaust tracts are added to the single cylinder, where pressure transducers and thermocouples are installed. In-cylinder pressure is measured at a resolution of 0.1 crank angle degree (CAD) by an AVL GH14D pressure sensor with a precision of $\pm 1 \%$ installed in the original diesel injector port. Fuel is fed to the intake port immediately after intake valve closure (IVC) to ensure full vaporization, and fuel flow rate is measured via the change in scale measurement over time, with a precision of $\pm 7 \%$ for the lowest fuel flow rate. Equivalence ratio is monitored using an automotive-type wide-band lambda sensor installed in the exhaust system with an uncertainty of \pm 0.015 . Temperature measurements are conducted using K-Type thermocouples with a manufacturer specified uncertainty of $\pm 2 \mathrm{~K}$. A more detailed description of the modified engine can be found in [36], while key engine specifications are summarized in Table 1.

Table 1. Key engine parameters and operating conditions.

UCB Engine Specifications 


\begin{tabular}{cccc}
\hline Compression Ratio & $16.5: 1$ & Fuel injection system & $\begin{array}{c}\text { Port fuel } \\
\text { injection }\end{array}$ \\
Displacement (litre) & 0.474 & Fuel injection pressure (bar) & 4 \\
Bore $(\mathrm{mm})$ & 81 & Number of valves per cylinder & 2 \\
Stroke $(\mathrm{mm})$ & 95.5 & Intake Valve Opening & $-20^{\circ} \mathrm{aTDC}$ \\
Connecting Rod Length $(\mathrm{mm})$ & 144 & Intake Valve Closing & $-140^{\circ} \mathrm{aTDC}$ \\
Coolant Temperature $\left({ }^{\circ} \mathrm{C}\right)$ & 105 & Exhaust Valve Opening & $140^{\circ} \mathrm{aTDC}^{\circ}$ \\
Oil Temperature $\left({ }^{\circ} \mathrm{C}\right)$ & 100 & Exhaust Valve Closing & $8^{\circ} \mathrm{aTDC}$ \\
\hline
\end{tabular}

\subsubsection{Experimental procedure}

During all engine experiments, equivalence ratio $(\phi)$, engine speed and combustion phasing (defined as CA50, the crank-angle where $50 \%$ of the total measured heat release has been achieved) are fixed at $0.3,1000 \mathrm{rpm}$ and $6^{\circ}$ aTDC, respectively. The intake pressure (Pin) is gradually increased from 0.9 to 1.6 bar at intervals of 0.1 bar. In each test with a specified intake pressure, the intake temperature (Tin) is adjusted to attain the targeted CA50. Thus, for less reactive conditions, a higher Tin is required, and for more reactive conditions, a lower Tin is required. To ensure repeatability, each operating point is measured twice, and at each engine operating condition 300 consecutive in-cylinder pressure traces are recorded.

\subsubsection{Data analysis}

During the post-processing, the 300 consecutive pressure traces are smoothed using a Savitzky-Golay filter of 19 points (i.e., 4.75 CAD window), and then averaged in order to calculate the rate of heat release (ROHR) and in-cylinder temperature profiles. The calculation of ROHR is conducted according to a procedure described in [33]. The method takes into account the engine parameters such as engine wall and piston head heat losses via a Woschni model [37], mass loss due to blow-by, pressure loss across the intake valve, IVC temperature, and changing specific heat ratios of the gas due to both temperature change as well as gas composition change from 
reactants to products. The values in the model are tuned using motoring pressure traces and a cycle simulation model in AVL BOOST, as described in [36]. In addition to the ROHR, the incylinder mass-averaged temperature is calculated using the ideal gas equation. A more detailed description of the methods can be found in [33].

The accuracy of the heat release analysis depends on a wide range of input parameters, including estimated gas compositions for determining heat capacity ratio, heat loss specified by the Woschni model and measured in-cylinder pressure, making quantifying uncertainty in engine hear release analysis complicated. Petipas et al. [38, 39] suggested that the uncertainty of accumulated heat release could be on the order of $\pm 10 \%$, which is confirmed to be a reasonable estimation by [34]. There are also challenges in calculating in-cylinder temperatures [40] as deploying ideal gas law requires accurate knowledge of in-cylinder composition and, more significantly, trapped mass [38] at various cycle points, which are often difficult to determine due to the unknown residual gas fraction and blow-by mass loss. The uncertainty of the calculated incylinder temperatures in this study is estimated at $\pm 10 \%$, similar to that reported in [38], while it is acknowledged that a range of gas temperatures exist across the combustion chamber due to imperfect mixing and heat loss at the walls, where fluctuations on the order of $\pm 4-10 \%$ are expected near TDC $[41,42]$.

Figure 2. In-cylinder pressure and calculated ROHR for 'neat' FACE-F at phi = 0.3, $1000 \mathrm{rpm}$, Pin = 1.6 bar and Tin $=61.5^{\circ} \mathrm{C}$, with no exhaust gas recirculation (EGR). Inset identifies LTHR.

The averaged in-cylinder pressure trace along with the corresponding calculated ROHR are presented in Fig. 2 for the case of Pin $=1.6$ bar. The inset shows the evolution of low temperature exothermicity. Onset of LTHR is observed at approximately $-20^{\circ} \mathrm{aTDC}$, where this exists for 
approximately 10 crank angles, up to the second inflection point demarcating the solTHR. ITHR occurs thereafter leading to the main heat release process. HTHR eventually causes the rapid pressure rise beginning at $\sim 4^{\circ}$ aTDC.

\subsection{Test Fuels and mixtures}

FACE- $F$ is selected as the base gasoline for this work. Detailed chemical and physical properties of FACE-F can be found in [15] and have been well documented in recent studies from KAUST $[11,43,44]$. It is a mid-octane fuel with an anti-knock index (AKI) of 91.6, which consists of relatively lower fractions of $n$-paraffinic and aromatics but higher fractions of naphthenes and olefins as compared to other FACE gasolines, leading to an octane sensitivity ( $\mathrm{S}=\mathrm{RON}$ minus MON) of 6.8. It is noted that this octane sensitivity is different from another study [15], as listed in Table 5. This discrepancy is within the reproducibility of RON and MON measurements specified by the ASTM standard [23, 24]. According to the Detailed Hydrocarbon Analysis of FACEF, major components of $n$-Paraffins, Iso-paraffins, Olefins, Naphthenes and Aromatics (PIONA) are $n$-heptane (C7), iso-octane (C8), 1-hexene (C6), cyclopentane (C5), and mixtures of ethylbenzene and xylenes (C8), respectively.

In this study, ethanol-blended gasolines are prepared by adding 10, 20 and 30 liquid volume percent of ethanol (Sigma Aldrich, 200 proof, anhydrous, $\geq 99.5 \%$ ) into FACE-F (E0), designated at E10, E20 and E30. In addition to E0, neat ethanol (E100) is used for comparison. The octane ratings of ethanol-blended gasolines have been measured in [11], and as seen in Table 2, increasing ethanol addition increases RON, MON, and octane sensitivity. 
Table 2. RON, MON and octane sensitivity of FACE-F and ethanol blends.

\begin{tabular}{|c|c|c|c|c|}
\hline Ethanol Volume \% & RON & MON & $S^{a}$ & LHV $^{b}$ \\
\hline $0[11]$ & 94.2 & 87.4 & 6.8 & 44.3 \\
\hline $10[11]$ & 98.9 & 88.5 & 10.4 & $N / A$ \\
\hline 25 [11] & 103.2 & 89.5 & 13.7 & N/A \\
\hline $40[11]$ & 104.7 & 90.3 & 14.4 & N/A \\
\hline $60[11]$ & 105.7 & 90.5 & 15.2 & N/A \\
\hline $100[14]$ & 109.0 & 90.0 & 19.0 & 26.9 \\
\hline
\end{tabular}

Each test fuel is studied in the RCM at two fuel loading conditions, one at diluted, stoichiometric fuel loading $\left(15 \% \mathrm{O}_{2}, \phi=1\right.$ (Mixes 1 and 2 in Table 3)) and the other at undiluted, lean fuel loading $\left(21 \% \mathrm{O}_{2}, \phi=0.3\right.$ (Mix 3 in Table 3)). The former is representative of boosted SI operation under elevated EGR scenarios, while the latter corresponds to the $\mathrm{HCCl}$ engine experiments. Initial pressure, temperature and diluent composition in the reaction chamber are adjusted to achieve a range of compressed conditions. Table 3 summarizes the mixture compositions, and corresponding Tc ranges. Detailed information for individual tests can be found in the supplementary material.

Table 3. Summary of fuel loading conditions used in this study.

\begin{tabular}{cccccc}
\hline Mixture \# & $\boldsymbol{\phi}$ & $\mathbf{O}_{\mathbf{2}}$ & $\mathbf{N}_{\mathbf{2}}$ & $\mathbf{A r}$ & Tc \\
\hline Mix 1 & 1.0 & $\sim 0.15$ & $\sim 0.84$ & 0.00 & $<830 \mathrm{~K}$ \\
Mix 2 & 1.0 & $\sim 0.15$ & $\sim 0.21$ & $\sim 0.63$ & $>830 \mathrm{~K}$ \\
Mix 3 & 0.3 & $\sim 0.21$ & $\sim 0.47$ & $\sim 0.31$ & $800-1000 \mathrm{~K}$ \\
\hline
\end{tabular}

\subsection{Model}

\subsubsection{FACE-F surrogates}

This study utilizes a 5-component surrogate for FACE-F to assist kinetic modeling of the autoignition process. Detailed philosophies of developing the surrogate blend, including 
selection of appropriate target properties and corresponding surrogate mixtures can be found in $[45,46]$, hence only key features of the proposed surrogate are described here. Instead of using simpler surrogates, such as a PRF or three-component, toluene primary reference fuels (TPRF), an array of constituents is utilized here and is beneficial to match octane qualities, as well as features such as a fuel's distillation curve [5]. Previous work [46] numerically formulated a fivecomponent surrogate for FACE-F (FGF-LLNL) with each component selected from five structural families where carbon type, molar $\mathrm{H} / \mathrm{C}$ ratio, $\mathrm{AKI}$ and octane sensitivity (S) were the target properties selected. Two correlations were utilized to estimate AKI and S: first, between homogeneous gas-phase ignition delay times at $825 \mathrm{~K}$ and $25 \mathrm{~atm}$ and $\mathrm{AKI}$; and second, between the minimum slop of the NTC region and S. The compositional makeup and target properties of FGF-LLNL are compared to FACE-F in Tables 4 and 5, respectively.

Table 4 also includes an 11-component surrogate (FGF-ANL), which is employed to estimate the specific heat, distillation curve and LHV of FACE-F. The more detailed surrogate is based on matching components similar to those identified in the detailed hydrocarbon analysis [15], and is used for Tc estimation, gauging condensation extents and calculation of HRR, respectively. The thermochemistry is taken from the NIST database [47], though it should be noted that this 11-component surrogate is not used for kinetic modeling in this study, and the heat capacities are only slightly different (as seen in the Supplementary Material, Fig. S1).

Table 4. Mole percents of FACE-F [45], FGF-LLNL [46] and FGF-ANL.

\begin{tabular}{ccccc}
\hline Structural Family & FACE-F & Palette Compound & FGF-LLNL & FGF-ANL \\
\hline$n$-Paraffins & 4.8 & $n$-Butane & 0 & 2.8 \\
\hline & & $n$-Heptane & 7 & 1.9 \\
\hline Iso-paraffins & 61.0 & 2-Methyl butane & 0 & 9.6 \\
\hline & & 3-Methyl pentane & 0 & 6.5 \\
\hline & & 2-Methyl hexane & 0 & 12.3 \\
\hline Olefin & 10 & Iso-octane & 53 & 32.8 \\
\hline & 1-Hexene & 14 & 9.6 \\
\hline
\end{tabular}




\begin{tabular}{ccccc} 
Naphthenes & 15.8 & Cyclopentane & 14 & 15.1 \\
\hline Aromatics & 8.4 & Toluene & 12 & 0.6 \\
\hline & Xylene & 0 & 8.3 \\
\hline & & 124-Trimethylbenzene & 0 & 0.5 \\
\hline
\end{tabular}

Table 5. Properties of FACE-F and FGF-LLNL [15].

\begin{tabular}{c|cc}
\hline & FACE-F & FGF-LLNL \\
\hline RON & 94.4 & 93.8 \\
MON & 88.8 & 89.5 \\
AKI $^{\mathbf{a}}$ & 91.6 & 91.6 \\
$\mathbf{S}^{\mathbf{b}}$ & 5.6 & 4.3 \\
Density (kg/m $\left.{ }^{3}\right)$ & 707 & 712 \\
$\mathbf{H} / \mathbf{C}$ & 2.13 & 2.06 \\
$\mathbf{M W}$ (g/mol) & 94.8 & 100.2 \\
\hline
\end{tabular}

\subsubsection{LLNL gasoline surrogate model}

The gasoline surrogate model used in this study is briefly described here. Readers are encouraged to find more detailed accounts in Mehl et al. [29] and a separate forthcoming publication on model development and validation. The core chemistry submodel, $\mathrm{CO}-\mathrm{C} 4$, is replaced with the recent Aramco 2.0 mechanism developed by NUI Galway [48]. Chemistry for alkanes $\mathrm{C} 5-\mathrm{C} 7$ has been recently updated by Bugler et al. [49] and Zhang et al. [50, 51]. The isooctane submodel has been revised, incorporating the work of Atef et al. [52] and new iso-alkane rate rules developed from a study of hexane isomers [53]. Submodels for aromatic compounds such as toluene, benzene, and phenol have been extensively rewritten to reflect changes made in recent studies [54-56]. Cyclopentane chemistry has been included from the work of Al Rashidi et al. [57-59]. Simulations of the RCM ignition delay times are completed using the LLNLdeveloped fast solver ZeroRK [60], including volume histories in non-reactive tests accounting for compression and heat loss. 


\section{RESULTS}

\subsection{Diluted, stoichiometric condition - RCM}

Tests are conducted at two iso-baric conditions ( $\mathrm{Pc}=23$ and 43 bar) covering $\mathrm{Tc}=700-$ $1000 \mathrm{~K}$. Figure 3 illustrates representative experimental and modeled pressure-time histories at $\mathrm{Pc}=43$ bar and two compressed temperatures, $\mathrm{Tc}=760$ and $908 \mathrm{~K}$, within the lowtemperature/NTC, and intermediate-temperature regimes, respectively. Two repeated shots fired at each experimental condition show great consistency, with excellent agreement also exhibited compared to the non-reactive experiments. Although the rates of pressure rise are similar at HTHR, the peak pressures are somewhat lower with higher ethanol addition, due to the slightly lower energy content of these fuels.

Figure 3. Experimental and modeled pressure-time histories for non-reacting and reacting mixtures of FACE-F/EOE30, illustrating the influence of ethanol addition into FACE-F at $\mathrm{PC}=43 \mathrm{bar}$, and the diluted/stoichiometric condition; (a) Tc = $760 \mathrm{~K}, \mathrm{Mix} 1$ and (b) $908 \mathrm{~K}$, Mix 2. Colored lines indicate measurement; grey lines are model results.

At Tc $=760 \mathrm{~K}$ (Figure 3a), two-stage ignition is observed for all test fuels. It is evident that ethanol retards both first-stage and main ignition times, indicating increased autoignition resistance which could be beneficial under analogous engine operating conditions. Interestingly, the magnitudes of perturbation do not linearly correspond to the volume of ethanol addition, as increasing ethanol concentration progressively provides more reactivity suppression. The nonlinear blending behavior observed here is consistent with other studies $[11,21]$ that investigated ethanol blending effects on gasoline fuels in engine environments. Figure $3 a$ also shows that ethanol non-linearly diminishes the magnitude of pressure rise in first-stage ignition, most likely due to ethanol acting as a radical sink at low-temperature/NTC, as will be discussed in detail in 
later sections. At Tc $=908 \mathrm{~K}$ (Figure $3 \mathrm{~b}$ ), the response to ethanol blending is quite different than at the lower temperature condition. The perturbations are significantly muted, with only slight changes in $\tau$.

Figure 3 also shows simulated pressure-time histories which are able to capture the qualitative effects of ethanol addition, including retarded first-stage and main ignition delay times and suppressed pressure rise from $\tau_{1}$. Noticeably, the magnitudes and progressions to the pressure rise in first-stage ignition appear to be similar between the measurements and the simulation. However, quantitative disagreements are observed. The model tends to overpredict the reactivity of all fuels studied at the lowest temperature condition (Fig. 3(a)), with discrepancies in total ignition delay time increasing as ethanol is blended to the gasoline surrogate. Such increased discrepancies with ethanol addition suggest possibilities that: (a) interactions between the ethanol sub-chemistry and that of these surrogate components in the chemistry model requires further improvement; (b) the surrogate makeup is not adequate to represent the full boiling range gasoline and needs to be reformulated; or (c) both. It is unclear which prospect is the major cause because it is possible that the model is able to accurately capture the ignition behavior of surrogate (FGF-LLNL)/EtOH blends whereas the surrogate fails to reproduce the ethanol blending effects on FACE-F since it is formulated targeting neat FACEF. Determining this will first require direct comparison of experiment results between FACEF/EtOH and FGF-LLNL/EtOH blends, which is beyond the scope of this work, but will be included in a future study. It should be noted that the quantitative disagreements between the model and experiments will not affect the following kinetic analyses as the ethanol blending effects are qualitatively captured by the model. 
Figure 4. Experimental and modeled ignition delay times at (a) $P c=23$ bar and (b) $P c=43$ bar, presented as functions of inverse temperature; Symbols indicate experiment (open - first-stage; close - second stage) and lines indicate model results.

Figure 4 summarizes the measured and simulated first-stage and main ignition delay times for FACE-F(FGF-LLNL)/E0-30 and E100 as functions of inverse temperature for $\mathrm{PC}=23$ and 43 bar. At both pressures it can be seen that the autoignition behavior of the neat fuel exhibits typical low-temperature, NTC and intermediate-temperature behavior [22] where reactivity of the first-stage of ignition increases monotonically with temperature, with the time between $\tau_{1}$ and $\tau$ steadily growing as Tc increases, until LTHR disappears. Pressure is observed to increase the reactivity of the mixture, yielding shorter $\tau_{1}$ and $\tau$, while the peak of the NTC is shifted to higher temperatures. These features are attributed to changes in the branching ratio towards ketohydroperoxide chain branching pathways at higher pressures, which starts with the production and isomerization of alkylperoxy and hydroperoxyalkylperoxy radicals instead of lowpressure prone reactions, including concerted elimination and $\beta$-scission [34], which produce less active intermediates (e.g., alkenes, $\mathrm{HO}_{2}$ ).

As with Fig. 3, the discussion of ethanol-blending effects is next divided between the lowtemperature/NTC regime ( $700 \mathrm{~K}<\mathrm{Tc}<850 \mathrm{~K}$ ), and the intermediate-temperature regime ( $850 \mathrm{~K}$ $<$ Tc $<1000 \mathrm{~K})$. In the low-temperature/NTC regime, ethanol strongly suppresses fuel reactivity, where it can be seen that the E100 mixture suppresses reactivity so severely that ignition delays are not able to be measured at many conditions. Consistent with Fig. 3a, ethanol is seen to suppress first-stage reactivity across the entire temperature range explored, even terminating LTHR at some conditions. An example can be seen at Tc $=780 \mathrm{~K}$, where $20 \%$ ethanol vol./vol. 
addition mutes the first-stage ignition, so that the autoignition process proceeds in a single-stage ignition manner. The reduction in low-temperature reactivity has been explained by the increased flux towards the Waddington pathway [8] as well as concerted elimination of hydroxyethyl radicals, where ethanol consumes $\mathrm{O}_{2}$ and $\mathrm{OH}$ radicals and leads to $\mathrm{HO}_{2}$ and aldehydes that are stable at low temperatures. In addition, the reduced amount of available $\mathrm{O}_{2}$ due to ethanol competition is expected to force other parent radicals generated from $\mathrm{H}$-atom abstraction of the fuel components to undergo $\beta$-scission, leading production of unreactive olefins.

In the intermediate-temperature regime, all test fuels display markedly Arrhenius behavior. Furthermore, a reversed trend of reactivity is observed in this temperature regime where E100 becomes more reactive at higher temperatures. The influence of ethanol addition though, is much weaker at these conditions where measured ignition delay times for FACE-F/EOE30 are almost identical, regardless of concentrations of ethanol in the base gasoline. These trends can be primarily attributed to the increased $\mathrm{HO}_{2}$ production from ethanol addition. At intermediate temperatures where $\mathrm{H}_{2} \mathrm{O}_{2}$ and $\mathrm{HO}_{2}$ reactions dominate, $\mathrm{SC} 2 \mathrm{H} 4 \mathrm{OH}$ radicals yielded from $\mathrm{H}$-atom abstraction of ethanol lead to increased $\mathrm{HO}_{2}$ production via $\mathrm{SC} 2 \mathrm{H} 4 \mathrm{OH}+\mathrm{O} 2=\mathrm{CH} 3 \mathrm{CHO}+\mathrm{HO} 2$. The produced $\mathrm{HO}_{2}$ radicals in turn participate in $\mathrm{H}$-atom abstraction reactions, which produces $\mathrm{H}_{2} \mathrm{O}_{2}$ radicals that further decompose into two $\mathrm{OH}$ radicals. This $\mathrm{OH}$ branching pathway (will be discussed in detail in flux analysis) leads to the higher reactivity of neat ethanol at intermediate temperatures. Additionally, the increasingly important thermal decompositions of ethoxy radical $\left(\mathrm{C}_{2} \mathrm{H}_{5} \mathrm{O}\right)$ and $\alpha$-hydroxyethyl $\left(\mathrm{CH}_{3} \mathrm{CHOH}\right)[8]$ leads to the production of reactive radicals such as $\mathrm{OH}, \mathrm{H}$ and $\mathrm{CH}_{3}$ at higher temperatures. 
The experimental findings presented here agree with previous work on low-temperature autoignition of ethanol-blended FACE-A, FACE-C and PRF 84 [21], wherein increased ethanol blending decreased fuel reactivity, leading to longer $\tau_{1}$ and $\tau$. The measurements are also consistent with intermediate-temperature autoignition of iso-octane/ethanol blends [10, 61-63] where neat ethanol displayed a stronger reactivity than both neat iso-octane and the blends. Reactivity differences due to ethanol blending in iso-octane at Tc $>870 \mathrm{~K}$ were also highlighted in $[10,62]$, where it was demonstrated that E20 had longer ignition delay times than E50. Additionally, the autoignition characteristics of FACE-F/EO, including NTC behavior, associated two-stage ignition features at lower temperatures, Arrhenius behavior at intermediate temperatures, and influences of pressure, agree with previous work [44], as demonstrated in the Supplementary Material (Fig. S2).

The model results for FGF-LLNL/EO shown in Fig. 4 captures the experimental measurements of FACE-F/EO fairly well at both pressures, though there are some discrepancies. At Tc $<750 \mathrm{~K}$ and $\mathrm{Tc}>850 \mathrm{~K}$ the kinetic model is somewhat more reactive while the influence of pressure seems to be greater than in the data. Nevertheless, fair agreement is observed for FGFLLNL/E10-E30. The impact of ethanol addition on first-stage and main ignition is captured by the model at both pressures over the entire temperature range. However, the model predicts less profound NTC behavior than the experiments, leading to over-predicted and under-predicted ignition delay times within and outside the NTC region, respectively, for E10 and consistently shorter ignition delay times for E20 and E30. In contrast to the low-temperature measurements, ignition delay times at intermediate-temperatures are better captured by the surrogate model. On the other hand, some reactivity differences between EO-E30 are seen in the simulation results 
in this temperature regime, which is different from the experimental observations. Overall, the level of agreement in the autoignition trends is reduced with higher extents of ethanol blending, similar to that observed in Fig. 3.

Figure 5. Calculated, normalized experimental and modeled heat release rates presented as functions of accumulated heat release for reacting mixtures of FACE-F (FGF-LLNL)/E0-E30, illustrating the influence of ethanol addition into FACE-F (FGF-LLNL) at Pc $=43$ bar, and the diluted/stoichiometric condition; (a) Tc $=760 \mathrm{~K}$ and (b) $908 \mathrm{~K}$. Insets depict preliminary exothermicity with LTHR and ITHR demarcations identified, i.e., solTHR and soHTHR, respectively. Color lines are experimental results; gray lines are model results. Each mixture has two experimental curves that represent two reactive tests performed. Experimental and modeled heat release rates for each blend are provided in separate figures in the Supplementary Material.

To better elucidate the impact of ethanol addition on the exothermic behavior during autoignition, LHV-normalized heat release rates are presented in Fig. 5 as functions of accumulated heat release for the same conditions as in Fig. 3. Figures for each blend are provided as Supplementary Material to allow better comparison between simulations and experiments (Figs. S3\&S4). The HRR trajectories start at the origin and evolve from left to right. Preliminary exothermicity including LTHR and ITHR (defined in Section 2.1.4), whenever applicable, can be identified at the lower left corner of the plot. Detailed discussion of these behaviors can be found in $[31,34]$. In general, several features are evident in Fig. 5, including substantial fluctuations in HTHR, where this is caused by the limited number of data points available during rapid HRR, and the peak values of aHR being less than 1.0. The latter is due to assumptions made in computing HRR, where the exothermically-induced energy losses, e.g., heat transfer to the walls and gas transfer to the crevice, are not fully taken into account in the calculation [31].

At the lower temperature $(T c=760 \mathrm{~K})$ the inset highlights LTHR and ITHR where solTHR and SOHTHR are demarcated, as with Fig. 3a. Ethanol blending reduces the peak HRR during 
LTHR, while the accumulated amount is also reduced (e.g., 0.08 to $0.01 / \mathrm{ms}$, and 5 to $3 \%$, respectively for blending to E30). Indeed, for FACE-F/E30, the evolution of LTHR is barely discernable at this compressed temperature. On the other hand, ethanol blending has almost no effect on the total preliminary heat release, i.e., LTHR+ITHR, where, even though LTHR is severely reduced, ITHR is magnified to compensate. This is consistent for the Tc $=908 \mathrm{~K}$ condition.

The model results shown in Fig. 5 indicate fairly good correspondence with the experimental measurements though there are some discrepancies in the magnitudes and extents of preliminary exothermicity and HTHR. Quantified LTHR and ITHR over the range of experimental conditions are presented next.

Figure 6. Calculated experimental and modeled accumulated LTHR and ITHR presented as functions of inverse temperature for reacting mixtures of FACE-F(FGF-LLNL)/EO-E30, illustrating the influence of ethanol addition into FACE-F at the diluted/stoichiometric condition; (a) $\mathrm{PC}=23$ bar and (b) $\mathrm{Pc}=43$ bar. Symbols indicate measurements; lines are model results.

Figure 6 presents the accumulated LTHR and LTHR+ITHR as functions of inverse temperature for FACE-F(FGF-LLNL)/EO-E100 at Pc $=23$ and 43 bar. Over the entire range of the dataset, it can be seen that the preliminary exothermicity is greatly enhanced at lower temperatures due in part to the rise of heat releasing reactions, such as $\mathrm{R}+\mathrm{O} 2=\mathrm{RO} 2$ and $\mathrm{RH}+\mathrm{OH}=\mathrm{R}+\mathrm{H} 2 \mathrm{O}$, with the latter as a result of significant quantities of $\mathrm{OH}$ generated from ketohydroperoxide decomposition. At both pressures, ethanol displays different influences on LTHR and LTHR+ITHR, where blending ethanol into FACE-F significantly decreases accumulated LTHR, while there is little suppressing influence on LTHR+ITHR. (Note that the scatter in the data at $\mathrm{Pc}=23$ bar is due to larger uncertainties in the measurements caused by long ignition times 
which leads to degradations in the adiabatic core assumption.) Neat ethanol (E100) interestingly exhibits the lowest extents of ITHR for the fuels tested, and this may be a function of the shorter explosive timescales at these conditions [64].

The gasoline surrogate model for FGF-LLNL appears to do a reasonable job capturing the trends in preliminary exothermicity, especially LTHR for the neat fuels and the ethanol-blended gasolines. There are greater discrepancies between the model and experimental values for LTHR+ITHR, which may be caused by the mechanism not being validated against heat release data, as well as the greater uncertainties in the derived ITHR values, as discussed in [31]. Nevertheless, the capability of the model to capture the trends in ethanol-blending is encouraging.

\subsubsection{Sensitivity and Flux Analyses}

Brute force sensitivity analysis on the ignition delay time is conducted for FGF-LLNL/EO and FGF-LLNL/E2O at the same conditions as in Fig. 3 and 5 using variable volume simulations. The sensitivity coefficients are defined as $S_{r e l}=\ln \left(\frac{\tau^{\Delta}}{\tau}\right) / \ln \left(\frac{k^{\Delta}}{k}\right)$, where $\tau^{\Delta}$ is the main ignition delay time after multiplying the original rate constant by 2 , i.e.,. $k^{\Delta}=2 * k$, and $\tau$ is the original ignition delay time. Negative sensitivity coefficients indicate that the reaction promotes reactivity, while positive coefficients indicate an inhibiting effect. Figure 7 presents the computed sensitivity coefficients for the 20 most sensitive reactions. The species participating in these reactions can be identified in the species dictionary in the supplementary material.

Figure 7. Sensitivity analysis on ignition delay time for FGF-LLNL/EO and FGF-LLNL/E20 at Pc $=43$ bar, and the diluted/stoichiometric condition; (a) Tc $=760 \mathrm{~K}$ and (b) $908 \mathrm{~K}$. The participating species can be identified in the species dictionary in the supplementary material. 
At $\mathrm{Tc}=760 \mathrm{~K}$ (Fig. 7a), the reaction classes of major importance include $\mathrm{HO}_{2}$ radical pathways, decomposition of $\mathrm{H}_{2} \mathrm{O}_{2}$ radical, $\mathrm{H}$-atom abstraction by $\mathrm{OH}$ radical from the parent fuels, concerted elimination of $\mathrm{HO}_{2}$ from $\mathrm{RO}_{2}$ radicals, and $\mathrm{O}_{2}$ addition to $\mathrm{QOOH}$ radicals. The sensitive reactions are dominated by iso-octane, $\mathrm{n}$-heptane and cyclopentane chemistries for FGF-LLNL/E0, and also by ethanol chemistry for FGF-LLNL/E20, with minor contributions from toluene and 1-hexene chemistries for both fuel blends despite their significant concentrations in FGF-LLNL (Table 4). The effects of ethanol addition are significant at Tc $=760 \mathrm{~K}$. First, the most inhibiting reaction for FGF-LLNL/EO is $\mathrm{HO} 2+\mathrm{HO} 2=\mathrm{H} 2 \mathrm{O} 2+\mathrm{O} 2$, whereas for FGF-LLNL/E2O, it is the $\mathrm{H}$-atom abstraction from ethanol by $\mathrm{OH}$ forming $\alpha$-hydroxyl ethanol radical $(\mathrm{SC} 2 \mathrm{H} 4 \mathrm{OH})$. The produced $\mathrm{SC} 2 \mathrm{H} 4 \mathrm{OH}$ radical leads to greater yield of aldehyde $+\mathrm{HO}_{2}$ [8], resulting in a significantly longer ignition delay, as seen in Fig. 3a. Second, the dependence of the low-temperature reactivity on FGF-LLNL chemistry is more pronounced with ethanol addition, which is seen from the greater sensitivity coefficients consistently observed for FGF-LLNL/E20 in Fig. 7a

At Tc $=908 \mathrm{~K}$ (Fig. $7 \mathrm{~b}$ ), there is a shift in the order of importance to the reactions involving $\mathrm{HO}_{2}$ and $\mathrm{H}_{2} \mathrm{O}_{2}$ chemistry. At this temperature, $\mathrm{H}$-atom abstractions from the parent fuels by $\mathrm{HO}_{2}$ forming $\mathrm{H}_{2} \mathrm{O}_{2}$ promote reactivity, while those by $\mathrm{OH}$ forming $\mathrm{H}_{2} \mathrm{O}$ generally inhibit reactivity. The former is due to the ability of $\mathrm{H}_{2} \mathrm{O}_{2}$ to undergo unimolecular decomposition to form two highly reactive $\mathrm{OH}$ radicals. The combination of two $\mathrm{HO}_{2}$ radicals yielding one $\mathrm{H}_{2} \mathrm{O}_{2}$ radical is the most inhibiting reaction at this temperature. This is somewhat counterintuitive since the produced $\mathrm{H}_{2} \mathrm{O}_{2}$ will mostly decompose into $\mathrm{OH}$ radicals. However, this reaction competes with the $\mathrm{H}$-atom abstraction by $\mathrm{HO}_{2}$, which could instead form two $\mathrm{H}_{2} \mathrm{O}_{2}$ radicals from two $\mathrm{HO}_{2}$ radicals leading to a higher $\mathrm{OH}$ branching rate. While the most sensitive reactions are still dominated by iso-octane 
and cyclopentane chemistries, toluene and 1-hexene chemistries become more prominent due to their increased reactivity at this temperature. Also seen in Fig. $7 \mathrm{~b}$ are the notable effects of ethanol. With 20 vol\% ethanol addition, the $\mathrm{H}$-atom abstractions from the $\alpha$-carbon site of ethanol by $\mathrm{OH}$ and $\mathrm{HO}_{2}$ radicals become the most sensitive among this reaction class, and sensitivity coefficients are reduced almost for all reactions, which is contrary to the $T c=760 \mathrm{~K}$ case. The results for FGF-LLNL/EO presented here are consistent with the previous modeling study on FGF-LLNL autoignition at $\mathrm{Pc}=20$ bar and Tc $=725$ and $925 \mathrm{~K} \mathrm{[5].}$

Sensitivity analysis is further conducted on the maximum rate of LTHR for FGF-LLNL/EO and FGF-LLNL/E20 at TC $=760 \mathrm{~K}$ and PC $=43$ bar. A similar definition $\left(S_{\text {rel }}=\ln \left(\frac{\text { MaxLTHR }}{M}\right) /\right.$ $\left.\ln \left(\frac{k^{\Delta}}{k}\right)\right)$ is used to compute the sensitivity coefficients, and a nominal value of $1.0 \mathrm{~J} / \mathrm{s}$ is used for MaxLTHR if LTHR is not observed in the perturbed simulations. The results are presented in Fig. 8, where negative sensitivity coefficients indicate that the reaction inhibits LTHR, while positive coefficients indicate a promoting effect.

Figure 8. Sensitivity analysis on maximum rate of LTHR for FGF-LLNL/EO and FGF-LLNL/E20 at TC $=760 \mathrm{~K}, \mathrm{PC}=43$ bar, and the diluted/stoichiometric condition. The participating species can be identified in the species dictionary in the supplementary material.

The controlling effect of LTHR on low-temperature reactivity is first seen for both fuel blends from the similar sensitive reactions between Fig. 7a and 8, where the reactions inhibiting and promoting LTHR consistently suppress and enhance low-temperature reactivity, respectively. The case is however different for $\mathrm{H} 2 \mathrm{O} 2(+\mathrm{M})=\mathrm{OH}+\mathrm{OH}(+\mathrm{M})$ (not shown in Fig. 8), which displays a strong promoting effect on ignition in Fig. 7a, but insignificant impacts on LTHR (a positive sensitivity coefficient of 0.007 and 0.02 on LTHR is obtained for this reaction for FGF- 
LLNL/EO and FGF-LLNL/E20, respectively). Finally, LTHR is significantly suppressed by ethanol via the $\mathrm{H}$-atom abstraction reaction consuming an $\mathrm{OH}$ radical to form $\mathrm{SC} 2 \mathrm{H} 4 \mathrm{OH}$. Doubling the rate of this reaction even mutes completely the LTHR in FGF-LLNL/E20 ignition, resulting in a sensitivity coefficient of nearly -13.2 .

Flux analyses are carried out for $\mathrm{OH}$ radical at peak $\mathrm{LTHR}$ and $\mathrm{HO}_{2}$ radical at $20 \%$ isooctane consumption, for FGF-LLNL/EO and FGF-LLNL/E20 at the same conditions as in Fig. 7. Variable volume simulations are used, and $\mathrm{OH}$ and $\mathrm{HO}_{2}$ radicals are selected due to their significance in controlling low- and intermediate-temperature reactivity, respectively. Figure 9 presents the flux analysis results covering only the most dominant pathways, while fluxes of other less dominant ones can be found in the supplementary material. The percentages shown in Fig. 9 are computed as the ratio of the rate of consumption (or production) for that pathway to the total rate of consumption (or production).

For FGF-LLNL/EO at TC $=760 \mathrm{~K}$ (italic numbers in Fig. 9a), $\mathrm{OH}$ radicals are mainly produced from cyclization of various $\mathrm{IC} 80 \mathrm{OH}$ radicals yielding cyclic ethers, and unimolecular decomposition of $\mathrm{C} 6 \mathrm{H} 12 \mathrm{OH}-\mathrm{O} 2$ (including both $\mathrm{C} 6 \mathrm{H} 12 \mathrm{OH}-1 \mathrm{O} 2-2$ and $\mathrm{C} 6 \mathrm{H} 12 \mathrm{OH}-2 \mathrm{O} 2-1$ ), which is formed via combination reactions of 1-hexene with an $\mathrm{OH}$ radical first and then a molecular $\mathrm{O}_{2}$. Sensitivity analysis results show that the latter pathway for $\mathrm{OH}$ production has negligible impacts on both LTHR and ignition reactivity, due to the zero net production of $\mathrm{OH}$ radical. At Tc $=908 \mathrm{~K}$ (bold numbers in Fig. 9a), the decomposition of $\mathrm{H}_{2} \mathrm{O}_{2}$ becomes the most dominant pathway for $\mathrm{OH}$ production, though it has a negligible contribution at $\mathrm{Tc}=760 \mathrm{~K}$. The change in role of this reaction in $\mathrm{OH}$ production across different temperatures is consistent with the sensitivity analysis results presented in Fig. $7 \mathrm{~b}$ and 8 . At both temperatures, the produced $\mathrm{OH}$ radicals are almost 
completely consumed via $\mathrm{H}$-atom abstractions from the parent fuels. Of these fuels, iso-octane and cyclopentane account for $>45 \%$ and $>14 \%$ of the $\mathrm{OH}$ consumption, respectively. Despite the similar branching ratio of these $\mathrm{H}$-atom abstraction pathways at both temperatures, the absolute rates of consumption are greatly reduced from $\mathrm{Tc}=760 \mathrm{~K}$ to $908 \mathrm{~K}$, e.g. by $\sim 66 \%$ for IC $8+\mathrm{OH}=\mathrm{IC} 8-$ $1 \mathrm{R}+\mathrm{H} 2 \mathrm{O}$, which results in the relatively smaller sensitivity coefficients for these reactions at $\mathrm{Tc}=$ $908 \mathrm{~K}$ in Fig. 7b.

Figure 9a also shows the effects of ethanol blending on $\mathrm{OH}$ consumption and production. At both temperatures, adding ethanol into the base gasoline does not lead to significant changes in $\mathrm{OH}$ production. However, ethanol significantly alters the competition between the $\mathrm{OH}$ consuming pathways, where $\mathrm{C} 2 \mathrm{H} 5 \mathrm{OH}+\mathrm{OH}=\mathrm{SC} 2 \mathrm{H} 4 \mathrm{OH}+\mathrm{H} 2 \mathrm{O}$ is more favored over others, and becomes comparable to $\mathrm{I} C 8+\mathrm{OH}=\mathrm{IC} 8-1 \mathrm{R}+\mathrm{H} 2 \mathrm{O}$, the most dominant pathway for $\mathrm{OH}$ consumption without ethanol addition. This is due in part to the significant amount of ethanol present in the fuel blend relative to other component, as well as the weaker $\mathrm{C}-\mathrm{H}$ bond at the alpha site. This competition plays an important role in the low-temperature autoignition of FGF-LLNL/ethanol blends, as they are the top reactions controlling the low-temperature reactivity, as seen in Fig. 7a. The shift in $\mathrm{OH}$ consumption towards the formation of $\mathrm{SC} 2 \mathrm{H} 4 \mathrm{OH}$ due to ethanol blending initiates $\mathrm{OH}$ radical scavenging, which eventually leads to significantly reduced low-temperature reactivity.

Figure 9. Flux analysis for (a) $\mathrm{OH}$ at peak LTHR and (b) $\mathrm{HO}_{2}$ at $\sim 20 \%$ iso-octane fuel consumption for FGF-LLNL/E0 and FGF-LLNL/E20 at $\mathrm{PC}=43 \mathrm{bar}, \mathrm{TC}=760$ and $908 \mathrm{~K}$, and the diluted/stoichiometric condition. Numbers represent the percentage of $\mathrm{OH}$ or $\mathrm{HO}_{2}$ radical consumed or produced by that pathway. Italic numbers represent flux at 760 
$\mathrm{K}$, and bold numbers represents flux at $908 \mathrm{~K}$. The participating species can be identified in the species dictionary in the supplementary material.

Figure $9 \mathrm{~b}$ shows that for FGF-LLNL/EO, the major pathways for $\mathrm{HO}_{2}$ production at both temperatures are $\mathrm{HCO}+\mathrm{O} 2=\mathrm{CO}+\mathrm{HO} 2$, combination of $\mathrm{H}+\mathrm{O} 2$, and concerted elimination of $\mathrm{RO}_{2}$ radicals formed from cyclopentane (CPTO2J) and iso-octane (IC8-4O2R and TC4H9O2). Figure 7a shows that these $\mathrm{HO}_{2}$ elimination pathways inhibit the reactivity at $\mathrm{Tc}=760 \mathrm{~K}$. This is elaborated in Fig. 9b for $\mathrm{H}_{2} \mathrm{O}_{2}$ production reactions where the produced $\mathrm{HO}_{2}$ radicals are unable to significantly convert to $\mathrm{H}_{2} \mathrm{O}_{2}$ at $\mathrm{Tc}=760 \mathrm{~K}$, and are instead consumed mostly via the lowsensitivity reactions pertaining to small radical species, e.g. $\mathrm{CH} 3 \mathrm{O} 2+\mathrm{HO} 2=\mathrm{CH} 3 \mathrm{O} 2 \mathrm{H}+\mathrm{O} 2$ (not shown in Fig. 9b but in the supplementary material). Such pathways cut off the chain of reactions that could otherwise lead to low-temperature chain branching. Conversely, increasing Tc to 908 $\mathrm{K}$ significantly promotes $\mathrm{H}_{2} \mathrm{O}_{2}$ formation via $\mathrm{H}$-atom abstractions from the parent fuels by $\mathrm{HO}_{2}$. These reactions greatly promote reactivity, as shown in Fig. 7b.

The role of ethanol in both $\mathrm{HO}_{2}$ production and consumption is significant at both temperatures. Figure $9 \mathrm{~b}$ shows that with 20 vol\% ethanol addition, pathways from ethanol chemistry out compete those from the other chemistries in both $\mathrm{HO}_{2}$ production and consumption, particularly at $\mathrm{Tc}=908 \mathrm{~K}$. Adding ethanol further increases the flux of $\mathrm{H}_{2} \mathrm{O}_{2}$ production via $\mathrm{H}$-atom abstraction, which leads to increased $\mathrm{OH}$ production following the pathways shown in Fig. 9a, hence enhanced fuel reactivity.

\subsection{Undiluted, lean condition $-\mathrm{HCCl}$ engine/RCM}

\subsection{1. $\mathrm{HCCl}$ engine}


The intent of the engine experiments is to characterize/quantify fuel reactivity trends over a range of $\mathrm{HCCl}$-relevant operating conditions, which covers the NTC to intermediatetemperature range ( $\mathrm{T} \sim 850-1000 \mathrm{~K})$. The measurement results, which only include FACE-F/E0 here can be compared against similar tests with other gasolines, gasoline surrogates and ethanolblended fuels, e.g., [21]. As described in Section 2.2.2, Pin is swept from 0.9 to 1.6 bar with Tin adjusted to achieve CA50 $=6^{\circ}$ aTDC. Non-ideal phenomena, such as inhomogeneities, turbulence and trapped residuals, are unavoidable in the engine experiments, but can be minimized by properly selecting the engine operating regime. For instance, a high compression ratio (16.5:1) is adopted to minimize the extent of residuals; the engine is set to $1000 \mathrm{rpm}$ to reduce levels of turbulence; and port fuel injection is utilized to improve mixture homogeneity. By holding CA50 constant with a constant TDC volume, the operating regime is expected to represent a quasihomogeneous condition that is more comparable to the RCM experiments, though it is acknowledged that non-idealities can lead to complex initiation and propagation processes during autoignition [65-67].

Figure 10. (a) Estimated pressure-temperature trajectories for 'neat' FACE-F in the $\mathrm{HCCl}$ engine covering a range of intake conditions with the curves shown through the point of CA50; (b) calculated ROHR profiles shown at the same conditions plotted as functions of CAD. Inset in (b) highlights preliminary exothermicity.

Pressure-temperature trajectories and ROHR profiles computed from the averaged pressure traces at each condition are plotted in Fig. 10. The inflection points in Fig. 10a indicate the onset of HTHR, while the inset in Fig. 10b demonstrates preliminary exothermicity. Clearly seen here is the significant dependence of the trajectories and heat release characteristics on 
intake temperature and pressure. As Pin is increased and Tin decreased, the trajectories pass through a region relevant to boosted, LTC engine conditions, with increased residence times and reaction pathways that allow the development of both LTHR and ITHR. This trend is exhibited in the ROHR profiles in Fig. 10b, with greater preliminary exothermicity and slower transition to HTHR observed at high Pin and low Tin conditions.

Figure 11 presents the required Tin across different Pin to maintain CA50 at $6^{\circ}$ aTDC for FACE-F/EO. It should be noted that despite constant combustion phasing, equivalence ratio, and engine speed, higher Pin and lower Tin increase the mixture densities, leading to higher power output. This is seen in Fig. 10b where the highest ROHR is obtained at Pin $=1.6$ bar. As with the P-T trajectories in Fig. 10a, increased Pin requires lower Tin in order to maintain constant combustion phasing. Starting from the lowest pressure ( $\mathrm{Pin}=0.9 \mathrm{bar}$ ), the response to Pin changes is observed to follow a linear trend of decreasing Tin, where an inflection point occurs at $\mathrm{Pin} \approx 1.45$ bar. This inflection is where the in-cylinder charge enters the NTC regime and demarcates between single-stage and two-stage heat releases. At higher Pin, there is distinct LTHR in the ROHR analyses (Fig. 10b), which increases the overall reactivity and correspondingly deceases the Tin required to maintain constant CA50.

Figure 11. Required intake temperature for FACE-F / EO in the $\mathrm{HCCl}$ engine to maintain constant combustion phasing over a range of intake pressures.

\subsubsection{RCM}

To facilitate comparisons between the $\mathrm{HCCl}$ engine and RCM data, measurements are conducted for FACE-F/EO at the same fuel loading condition, covering similar compressed 
pressure and temperature conditions. Blends of E0-E30 are also used to infer how the engine would behave under such fuel changes. Figure 12 first presents the representative pressure-time histories for FACE-F/EO at TC $=855 \mathrm{~K}$ and PC $=15-80$ bar, where two test shots are shown at each compressed pressure, again highlighting the high level of consistency. Here, the mixture reactivity increases with increasing pressure. Through most of the Pc-Tc range the ignition process proceeds in a single-stage manner, but at higher pressures (e.g., $\mathrm{Pc}>60$ bar), there is an emergence of two-stage behavior. This is readily evident when comparing the reactive and nonreactive pressure traces. Also evident is the presence of piston rebound the highest pressures (Pc $>70$ bar), where there is a rapid drop in pressure after HTHR. This is caused by the insufficient time to transfer hydraulic fluid from the tpRCM's accumulator to engage the hydraulic lock. This feature does not affect the determination of $\tau$, or significantly affect the heat release analyses, as it occurs towards the end of HTHR. The slight effects on HRR and aHR are seen as an apparent loss in fuel energy of approximately $2-4 \%$ (see supplementary material in [34]).

Figure 12. Representative measured and modeled pressure-time histories for FACE-F/E0 (Mix 3) illustrating the influence of compressed pressure, covering $\mathrm{Pc}=15-80 \mathrm{bar}$, at $\mathrm{Tc}=855 \mathrm{~K}$. Two reacting traces are shown at each test condition, and these are nearly identical. Grey solid lines indicate non-reacting tests where the evolution of exothermicity can be seen. Grey dashed lines indicate corresponding model results.

Results of the chemical kinetic model are also shown in Fig. 12. Very good correspondence between the measurements and the simulations is observed, including the evolution of preliminary exothermicity and two-stage ignition, though the influence of pressure is seen to be somewhat stronger in the experimental data. Peak pressures in the measurements are lower than in the model due to inability of the adiabatic core framework to account for the greater heat loss caused by HTHR. 
The measurements for FACE-F/EO are summarized as a $\tau$-Tc-Pc surface in threedimensional fashion in Fig. 13, where projections on the two two-dimensional planes are isopleths of Pc and $\tau$. Three P-T compression trajectories ( $\mathrm{Pin}=0.9,1.3,1.6 \mathrm{bar}$ ) from the $\mathrm{HCCl}$ experiments are overlaid onto the surface, with stars at the ends of the trajectories indicating starts of main heat release in the engine, i.e., the inflection points in Fig. 10a. By comparing the engine trajectories with the RCM dataset, it is clear that the relevant conditions experienced in the $\mathrm{HCCl}$ engine are directly mapped by the autoignition regimes quantified in the RCM, indicating the possibility of using the RCM dataset to infer fuel behavior under the engine environment, as discussed in [34].

Figure 13. Experimentally measured $\mathrm{t}$-Tc-Pc surface for FACE-F/E0 (Mix 3) covering Tc $=800-1000 \mathrm{~K}$ and Pc $=15-$ $80 \mathrm{bar}$, with the $\mathrm{HCCl}$ engine compression trajectories overlaid. Stars at the ends of the trajectories indicate starts of main heat release in the engine.

To better elucidate this, isopleths of $\tau$ are next shown in Fig. 14 for FACE-F/EO in a pressure-temperature space, together with the three engine trajectories used in Fig. 13. Predicted isopleths from the model are also included in Fig. 14. Immediately evident from the measurements is the strong NTC behavior with accompanying changes in temperature sensitivity at Tc $<925 \mathrm{~K}$, where the trends shift with compressed pressure. As with Fig. 12, the model results shown in Fig. 14 indicate fairly good correspondence with the experiments through much of the domain. At lower temperatures however, the model does not properly capture the NTC behavior of the 'neat' full boiling range gasoline, while at intermediate temperatures, the model is slightly 
more reactive, where the spacings between the isopleths indicate that the model is more sensitive to pressure increases.

Using the $\tau$ isopleth map as reference, it is clear that the engine trajectory at Pin $=0.9$ bar lies within the intermediate-temperature chemistry regime where LTHR is not observed in the $\mathrm{RCM}$, while at Pin $=1.6$ bar, there is overlap between the engine trajectory and the NTC regime, corroborating the $\mathrm{HCCl}$ engine measurements where LTHR is observed at this intake condition.

Figure 14. Experimental and modeled isopleths of $\tau=2-72 \mathrm{~ms}$ for FACE-F(FGF-LLNL)/E0 covering Tc $=800-1000$ $\mathrm{K}$ and $\mathrm{Pc}=15-80$ bar where NTC behavior is observed at Tc $<925 \mathrm{~K}$. Estimated compression trajectories from $\mathrm{HCCl}$ engine are shown for Pin = 0.9, 1.3 and 1.6 bar.

The reasonable correlation between $\mathrm{RCM}$ and $\mathrm{HCCl}$ engine data suggests that the influence of ethanol addition can be characterized by changes in the isopleths of $\tau$. It is noted that the RCM conditions are more straightforward to simulate, and therefore the capabilities of the chemical model easier to confirm. This requires selecting a proper range of $\tau$ that is indicative of engine operation, and conditions necessary to maintain constant combustion phasing. For this work, an isopleth of $\tau=4 \mathrm{~ms}$ is chosen as it is close to the starts of main heat release in the $\mathrm{HCCl}$ engine in Fig. 14.

Figure 15. Experimental and modeled isopleths of $\tau=4 \mathrm{~ms}$ for FACE-F(FGF-LLNL)/E0-E30 (Mix 3) covering a range of compressed temperature and pressure illustrating the influence of ethanol blending with stronger perturbations due to ethanol observed at Tc $<925 \mathrm{~K}$ where NTC chemistry becomes important.

Measured and simulated isopleths of $\tau=4 \mathrm{~ms}$ are presented in Fig. 15 for FACE-F(FGFLLNL)/EO-E30 (note that the simulated values account for the piston compression process). Here, 
NTC behavior and the onset of LTHR/two-stage behavior occur at Tc $<925 \mathrm{~K}$, as indicated by the inflection points. The measurements indicate that at low pressures ( $\mathrm{Pc}<60$ bar), all test fuels, from FACE-F/E0 to FACE-F/E30, require nearly the same Tc, demonstrating negligible influence of ethanol blending. At Pc $>60$ bar, the onset of LTHR leads to altered temperature sensitivity where greater temperature adjustment is required to achieve a scenario of constant combustion phasing. This behavior is best represented by FACE-F/EO where the change in compressed temperature as compressed pressure changes is approximately $-1.8 \mathrm{~K} /$ bar when the pressure is below 60 bar, while $-44 \mathrm{~K} /$ bar above $\mathrm{Pc}=60$ bar. Contrary to the low-boost/intermediatetemperature regime, influences of ethanol blending are significant within this regime, with LTHR greatly suppressed by ethanol leading to severely reduced fuel reactivity. The most profound effect is observed for FACE-F/E30, where LTHR from the FACE-F chemistry is completely muted, resulting in a nearly linear isopleth over the entire data range. These behaviors are qualitatively captured by the model, but there are noticeable discrepancies at both intermediate-temperature and NTC conditions. The trends observed here are analogous to those seen at the diluted, stoichiometric conditions described in Section 3.1.

\section{SUMMARY AND CONCLUSIONS}

This study aims to provide necessary insights into the autoignition and preliminary exothermic behavior of FACE-F/ethanol blends across a wide range of engine-relevant conditions. New experimental data are acquired in an RCM at diluted/stoichiometric and undiluted/lean fuel loadings, compressed temperatures from 700 to $1000 \mathrm{~K}$, and compressed pressures from 15 to $80 \mathrm{bar}$, and in an $\mathrm{HCCl}$ engine at a lean fuel loading, covering a range of intake pressures where 
intake temperature is adjusted to fix combustion phasing. A recently updated gasoline surrogate model is also used in conjunction with a five-component FACE-F surrogate (FGF-LLNL) to conduct chemical kinetic modeling at the RCM conditions. Comprehensive analyses of the results indicate the following,

- Within the low-temperature regime, the RCM experiments reveal the NTC behavior and two-stage ignition for FACE-F/EO-30, and indicate that both first-stage and main ignition delay times are extended by ethanol, with the magnitudes of perturbation non-linearly correlated to ethanol concentration, and diminishing towards higher temperature and pressure. Influences of ethanol on LTHR and ITHR are also observed, with an increase in ethanol concentration significantly suppressing LTHR, while imposing minor influences on ITHR. The chemical model, in conjunction with the 5-component surrogate, shows good agreements with experiments in both autoignition and preliminary heat releases, with relatively greater discrepancies observed at higher levels of ethanol addition, indicating a need to further improve the relevant chemistry and possible surrogate formulation. Sensitivity analysis highlights the controlling effects on LTHR and lowtemperature reactivity, which are dominated by the $\mathrm{H}$-atom abstraction by $\mathrm{OH}$ from the parent fuels. Flux analysis indicates that adding ethanol causes a shift in the flux favoring the $\mathrm{H}$-atom abstraction from ethanol yielding $\mathrm{SC} 2 \mathrm{H} 4 \mathrm{OH}$, which aids progression towards $\mathrm{OH}$ termination that would otherwise lead towards $\mathrm{OH}$ branching. 
- Within the intermediate-temperature range, the RCM experiments show singlestage ignition, and the influences of ethanol blending are significantly muted, with only slight decreases in ITHR and main ignition as ethanol is blended into the fuel, opposite to the trend in the low-temperature regime. The model performs better in this temperature regime. Sensitivity analysis demonstrates the importance of $\mathrm{HO}_{2}$ and $\mathrm{H}_{2} \mathrm{O}_{2}$ chemistry, while flux analysis shows that adding ethanol facilitates $\mathrm{H}_{2} \mathrm{O}_{2}$ formation via $\mathrm{C} 2 \mathrm{H} 5 \mathrm{OH}+\mathrm{HO} 2 \Leftrightarrow=>\mathrm{SC} 2 \mathrm{H} 4 \mathrm{OH}+\mathrm{H} 2 \mathrm{O} 2$, which subsequently leads to increased $\mathrm{OH}$ production via $\mathrm{H}_{2} \mathrm{O}_{2}$ decomposition, hence increased autoignition reactivity.

- Under a constant combustion phasing scenario, the $\mathrm{HCCl}$ engine experiments are found to exhibit LTHR at high Pin (> 1.45 bar) and low Tin conditions, where more adjustment in Tin is required to maintain constant combustion phasing. By mapping the engine trajectories onto the isopleths of $\tau$, strong correspondence is observed for LTHR and soHTHR between the $\mathrm{HCCl}$ engine and RCM, with an isopleth of $\tau=4 \mathrm{~ms}$ reasonably marking the soHTHR in the $\mathrm{HCCl}$ engine. Comparing the isopleth of $\tau=4 \mathrm{~ms}$ for FACE-F/EO-30 indicates that ethanol influence on autoignition behavior is only significant in high-boost/low-temperature regime where LTHR is more likely to occur. Within this regime, ethanol greatly suppresses or even mutes LTHR, leading to reduced temperature sensitivities that are beneficial to practical engine control.

The observations comparing the $\mathrm{HCCl}$ engine and RCM data have practical implications. For instance, when intake pressure is boosted to achieve higher output, the engine compression 
trajectories move in P-T space. This results in a shift to a regime where low-temperature chemistry becomes important and LTHR occurs. Within this regime, fuels that exhibit similar or even identical reactivity at low-boosted conditions can have significantly different reactivity, e.g., FACE-F/EO-E30. Failure to predict and control such shifts can lead to detrimental consequences, as advanced combustion phasing accompanying LTHR can develop into extreme events under high fuel loading conditions, such as super-knock [63]. Reactivity control across the NTC regime where LTHR occurs can be challenging. Exploring fuel blends, such ethanol and other oxygenates, may facilitate suppression of LTHR for high load operation. However, these features are not adequately captured by historical fuel metrics (e.g., RON and MON) commonly used to quantify fuel reactivity. The development of new fuel metrics to reflect preliminary heat release characteristics across a wide range of engine-relevant conditions could prove beneficial. While running a vast engine campaign is expensive, and the coupling physical influences make chemistry interpretation challenging, RCM experiments offer the potential to explore new fuel metrics given the good correlation with the $\mathrm{HCCl}$ engine observed in this and other work [34].

\section{ACKNOWLEDGEMENT}

This manuscript has been created by UChicago Argonne, LLC, Operator of Argonne National Laboratory, a U.S. Department of Energy Office of Science laboratory, under Contract No. DE-AC02-06CH11357. The work at LLNL was performed under Contract DE-AC52-07NA27344. The U.S. Government retains for itself, and others acting on its behalf, a paid-up nonexclusive, irrevocable worldwide license in said article to reproduce, prepare derivative works, distribute copies to the public, and perform publicly and display publicly, by or on behalf of the 
Government. The DOE will provide public access in accordance with http://energy.gov/downloads/doe-public-access-plan. This work performed under auspices of the Office of Energy Efficiency and Renewable Energy, Office of Vehicle Technology, Gurpreet Singh, Leo Breton and Kevin Stork as program managers. The work at the University of California Berkeley was partially supported by NSF/DOE Award No. CBET-1258653 entitled "Advancing Low Temperature Combustion and Lean Burning Engines for Light- and Heavy-Duty Vehicles with Microwave Assisted Spark Plugs and Fuel Stratification."

The authors acknowledge the assistance of Dr. Jeffrey Santner, Dr. Toby Rockstroh and Mr. Tim Rutter for their efforts to maintain and operate ANL's tpRCM. Prof. S. Mani Sarathy (KAUST) is acknowledged for providing the FACE-F gasoline to ANL and UCB.

\section{REFERENCE}

[1] T.M. Foong, K.J. Morganti, M.J. Brear, G. da Silva, Y. Yang, F.L. Dryer, The octane numbers of ethanol blended with gasoline and its surrogates, Fuel 115 (2014) 727-739.

[2] M.N. Nabi, H. Ogawa, N. Miyamoto, Nature of Fundamental Parameters Related to Engine Combustion for a Wide Range of Oxygenated Fuels, SAE International, 2002.

[3] M. Brusstar, M. Stuhldreher, D. Swain, W. Pidgeon, High Efficiency and Low Emissions from a PortInjected Engine with Neat Alcohol Fuels, SAE International, 2002.

[4] U. Congress, Energy independence and security act of 2007, Public law 2 (2007) 110-140.

[5] D. Kang, A. Fridlyand, S.S. Goldsborough, S.W. Wagnon, M. Mehl, W.J. Pitz, M.J. McNenly, Autoignition study of FACE gasoline and its surrogates at advanced IC engine conditions, Proceedings of the Combustion Institute 37 (2019) 4699-4707.

[6] G.A. Richards, M.M. McMillian, R.S. Gemmen, W.A. Rogers, S.R. Cully, Issues for low-emission, fuelflexible power systems, Progress in Energy and Combustion Science 27 (2001) 141-169.

[7] A.K. Agarwal, A.P. Singh, R.K. Maurya, Evolution, challenges and path forward for low temperature combustion engines, Progress in Energy and Combustion Science 61 (2017) 1-56.

[8] S.M. Sarathy, P. Oßwald, N. Hansen, K. Kohse-Höinghaus, Alcohol combustion chemistry, Progress in Energy and Combustion Science 44 (2014) 40-102.

[9] P. Dagaut, C. Togbé, Experimental and modeling study of the kinetics of oxidation of ethanol-nheptane mixtures in a jet-stirred reactor, Fuel 89 (2010) 280-286.

[10] C.L. Barraza-Botet, M.S. Wooldridge, Combustion chemistry of iso-octane/ethanol blends: Effects on ignition and reaction pathways, Combustion and Flame 188 (2018) 324-336.

[11] J. Badra, A.S. AlRamadan, S.M. Sarathy, Optimization of the octane response of gasoline/ethanol blends, Applied Energy 203 (2017) 778-793. 
[12] H. Yuan, Y. Yang, M.J. Brear, T.M. Foong, J.E. Anderson, Optimal octane number correlations for mixtures of toluene reference fuels (TRFs) and ethanol, Fuel 188 (2017) 408-417.

[13] E. Singh, E.-A. Tingas, D. Goussis, H.G. Im, S.M.J.E. Sarathy, Fuels, Chemical ignition characteristics of ethanol blending with primary reference fuels, 33 (2019) 10185-10196.

[14] J.E. Anderson, U. Kramer, S.A. Mueller, T.J. Wallington, Octane Numbers of Ethanol- and Methanol-Gasoline Blends Estimated from Molar Concentrations, Energy \& Fuels 24 (2010) 6576-6585.

[15] W. Cannella, M. Foster, G. Gunter, W. Leppard, FACE gasolines and blends with ethanol: detailed characterization of physical and chemical properties, CRC Report No AVFL-24, (2014).

[16] C. Lee, A. Ahmed, E.F. Nasir, J. Badra, G. Kalghatgi, S.M. Sarathy, H. Curran, A.J.C. Farooq, Flame, Autoignition characteristics of oxygenated gasolines, 186 (2017) 114-128.

[17] L. Cai, A. Ramalingam, H. Minwegen, K. Alexander Heufer, H. Pitsch, Impact of exhaust gas recirculation on ignition delay times of gasoline fuel: An experimental and modeling study, Proceedings of the Combustion Institute 37 (2019) 639-647.

[18] M. Waqas, N. Naser, M. Sarathy, J. Feijs, K. Morganti, G. Nyrenstedt, B. Johansson, Auto-lgnition of Iso-Stoichiometric Blends of Gasoline-Ethanol-Methanol (GEM) in $\mathrm{SI}, \mathrm{HCCl}$ and $\mathrm{Cl}$ Combustion Modes, SAE International, 2017.

[19] M. Waqas, N. Naser, M. Sarathy, K. Morganti, K. Al-Qurashi, B. Johansson, Blending Octane Number of Ethanol in $\mathrm{HCCl}, \mathrm{SI}$ and $\mathrm{Cl}$ Combustion Modes, SAE International, 2016.

[20] M.U. Waqas, N. Atef, E. Singh, J.-B. MASURIER, M. Sarathy, B. Johansson, Blending Behavior of Ethanol with PRF 84 and FACE A Gasoline in $\mathrm{HCCl}$ Combustion Mmode, SAE International, 2017.

[21] D. Vuilleumier, N. Atef, G. Kukkadapu, B. Wolk, H. Selim, D. Kozarac, S. Saxena, Z. Wang, C.-J. Sung, R. Dibble, S.M. Sarathy, The Influence of Intake Pressure and Ethanol Addition to Gasoline on Single- and Dual-Stage Autoignition in an HCCl Engine, Energy \& Fuels 32 (2018) 9822-9837.

[22] S.S. Goldsborough, S. Hochgreb, G. Vanhove, M.S. Wooldridge, H.J. Curran, C.-J. Sung, Advances in rapid compression machine studies of low- and intermediate-temperature autoignition phenomena, Progress in Energy and Combustion Science 63 (2017) 1-78.

[23] A. International, Standard Test Method for Motor Octane Number of Spark-Ignition Engine Fuel, 2013.

[24] A. international. Standard Test Method for Research Octane Number of Spark-Ignition Engine Fuel, 2007.

[25] M.J. Pilling, Low-temperature combustion and autoignition, Elsevier1997.

[26] J.-S. Chen, T. Litzinger, H. Curran, The lean oxidation of iso-octane in the intermediate temperature regime at elevated pressures, Combustion science and technology 156 (2000) 49-79.

[27] M. Figueroa-Labastida, J. Badra, A.M. Elbaz, A. Farooq, Shock tube studies of ethanol preignition, Combustion and Flame 198 (2018) 176-185.

[28] G. Mittal, S.M. Burke, V.A. Davies, B. Parajuli, W.K. Metcalfe, H.J. Curran, Autoignition of ethanol in a rapid compression machine, Combustion and Flame 161 (2014) 1164-1171.

[29] M. Mehl, K. Zhang, S. Wagnon, G. Kukkadapu, C.K. Westbrook, W.J. Pitz, Y. Zhang, H.J. Curran, M. Al Rachidi, N. Atef, A comprehensive detailed kinetic mechanism for the simulation of transportation fuels, (2017).

[30] A. Fridlyand, S.S. Goldsborough, M. Al Rashidi, S.M. Sarathy, M. Mehl, W.J. Pitz, Low temperature autoignition of 5-membered ring naphthenes: Effects of substitution, Combustion and Flame 200 (2019) 387-404.

[31] S.S. Goldsborough, J. Santner, D. Kang, A. Fridlyand, T. Rockstroh, M.C. Jespersen, Heat release analysis for rapid compression machines: Challenges and opportunities, Proceedings of the Combustion Institute 37 (2019) 603-611.

[32] J.B. Heywood, Internal combustion engine fundamentals, (1988). 
[33] D. Vuilleumier, D. Kozarac, M. Mehl, S. Saxena, W.J. Pitz, R.W. Dibble, J.-Y. Chen, S.M. Sarathy, Intermediate temperature heat release in an $\mathrm{HCCl}$ engine fueled by ethanol/n-heptane mixtures: An experimental and modeling study, Combustion and flame 161 (2014) 680-695.

[34] T. Rockstroh, A. Fridlyand, S. Ciatti, W. Cannella, S.S. Goldsborough, Autoignition behavior of a full boiling-range gasoline: Observations in RCM and $\mathrm{GCl}$ engine environments, Combustion and Flame 209 (2019) 239-255.

[35] B.W. Weber, C.-J. Sung, M.W. Renfro, On the uncertainty of temperature estimation in a rapid compression machine, Combustion and Flame 162 (2015) 2518-2528.

[36] D.M. Vuilleumier, The Effect of Ethanol Addition to Gasoline on Low-and Intermediate-Temperature Heat Release under Boosted Conditions in Kinetically Controlled Engines, UC Berkeley, 2016.

[37] G. Woschni, A universally applicable equation for the instantaneous heat transfer coefficient in the internal combustion engine, Report No. 0148-7191, SAE Technical paper, 1967.

[38] G. Petitpas, M.J. McNenly, R.A. Whitesides, A Framework for Quantifying Measurement Uncertainties and Uncertainty Propagation in HCCI/LTGC Engine Experiments, SAE International Journal of Engines 10 (2017) 1275-1296.

[39] G. Petitpas, R. Whitesides, J. Dernotte, J. Dec, Refining Measurement Uncertainties in HCCI/LTGC Engine Experiments, Report No. 0148-7191, SAE Technical Paper, 2018.

[40] S. Cheng, Autoignition of pentane isomers in a spark-ignition engine: experiment \& modeling uncertainty quantification, 2019.

[41] C. Mandanis, M. Schmitt, J. Koch, Y.M. Wright, K. Boulouchos, Wall Heat Flux and Thermal Stratification Investigations during the Compression Stroke of an engine-like Geometry: A comparison between LES and DNS, Flow, Turbulence and Combustion 100 (2018) 769-795.

[42] B. Lawler, J. Lacey, N. Dronniou, J. Dernotte, J.E. Dec, O. Guralp, P. Najt, Z. Filipi, Refinement and Validation of the Thermal Stratification Analysis: A post-processing methodology for determining temperature distributions in an experimental $\mathrm{HCCl}$ engine, SAE International, 2014.

[43] B. Chen, Z. Wang, J.-Y. Wang, H. Wang, C. Togbé, P.E.Á. Alonso, M. Almalki, M. Mehl, W.J. Pitz, S.W. Wagnon, K. Zhang, G. Kukkadapu, P. Dagaut, S. Mani Sarathy, Exploring gasoline oxidation chemistry in jet stirred reactors, Fuel 236 (2019) 1282-1292.

[44] S.M. Sarathy, G. Kukkadapu, M. Mehl, T. Javed, A. Ahmed, N. Naser, A. Tekawade, G. Kosiba, M. AlAbbad, E. Singh, S. Park, M.A. Rashidi, S.H. Chung, W.L. Roberts, M.A. Oehlschlaeger, C.-J. Sung, A. Farooq, Compositional effects on the ignition of FACE gasolines, Combustion and Flame 169 (2016) 171193.

[45] S.M. Sarathy, G. Kukkadapu, M. Mehl, T. Javed, A. Ahmed, N. Naser, A. Tekawade, G. Kosiba, M. AlAbbad, E. Singh, Compositional effects on the ignition of FACE gasolines, Combustion and Flame 169 (2016) 171-193.

[46] M. Mehl, J.-Y. Chen, W.J. Pitz, S.M. Sarathy, C.K. Westbrook, An approach for formulating surrogates for gasoline with application toward a reduced surrogate mechanism for CFD engine modeling, Energy \& Fuels 25 (2011) 5215-5223.

[47] E. Lemmon, M. McLinden, D. Friend, P. Linstrom, W. Mallard, NIST chemistry webbook, NIST standard reference database, (2005) 20899.

[48] Y. Li, C.-W. Zhou, K.P. Somers, K. Zhang, H.J. Curran, The oxidation of 2-butene: A high pressure ignition delay, kinetic modeling study and reactivity comparison with isobutene and 1-butene, Proceedings of the Combustion Institute 36 (2017) 403-411.

[49] J. Bugler, B. Marks, O. Mathieu, R. Archuleta, A. Camou, C. Grégoire, K.A. Heufer, E.L. Petersen, H.J. Curran, An ignition delay time and chemical kinetic modeling study of the pentane isomers, Combustion and Flame 163 (2016) 138-156. 
[50] K. Zhang, C. Banyon, J. Bugler, H.J. Curran, A. Rodriguez, O. Herbinet, F. Battin-Leclerc, C. B'Chir, K.A. Heufer, An updated experimental and kinetic modeling study of $n$-heptane oxidation, Combustion and Flame 172 (2016) 116-135.

[51] K. Zhang, C. Banyon, C. Togbé, P. Dagaut, J. Bugler, H.J. Curran, An experimental and kinetic modeling study of n-hexane oxidation, Combustion and Flame 162 (2015) 4194-4207.

[52] N. Atef, G. Kukkadapu, S.Y. Mohamed, M. Al Rashidi, C. Banyon, M. Mehl, K.A. Heufer, E.F. Nasir, A. Alfazazi, A.K. Das, A comprehensive iso-octane combustion model with improved thermochemistry and chemical kinetics, Combustion and Flame 178 (2017) 111-134.

[53] K. Zhang, C. Banyon, U. Burke, G. Kukkadapu, S.W. Wagnon, M. Mehl, H.J. Curran, C.K. Westbrook, W.J. Pitz, An experimental and kinetic modeling study of the oxidation of hexane isomers: Developing consistent reaction rate rules for alkanes, Combustion and Flame 206 (2019) 123-137.

[54] Y. Zhang, K.P. Somers, M. Mehl, W.J. Pitz, R.F. Cracknell, H.J. Curran, Probing the antagonistic effect of toluene as a component in surrogate fuel models at low temperatures and high pressures. A case study of toluene/dimethyl ether mixtures, Proceedings of the Combustion Institute 36 (2017) 413-421. [55] G. Kukkadapu, D. Kang, S.W. Wagnon, K. Zhang, M. Mehl, M. Monge-Palacios, H. Wang, S.S. Goldsborough, C.K. Westbrook, W.J. Pitz, Kinetic modeling study of surrogate components for gasoline, jet and diesel fuels: C7-C11 methylated aromatics, Proceedings of the Combustion Institute 37 (2019) 521-529.

[56] S.W. Wagnon, S. Thion, E.J. Nilsson, M. Mehl, Z. Serinyel, K. Zhang, P. Dagaut, A.A. Konnov, G. Dayma, W.J. Pitz, Experimental and modeling studies of a biofuel surrogate compound: laminar burning velocities and jet-stirred reactor measurements of anisole, Combustion and Flame 189 (2018) 325-336. [57] M.J. Al Rashidi, J.C. Mármol, C. Banyon, M.B. Sajid, M. Mehl, W.J. Pitz, S. Mohamed, A. Alfazazi, T. Lu, H.J. Curran, A. Farooq, S.M. Sarathy, Cyclopentane combustion. Part II. Ignition delay measurements and mechanism validation, Combustion and Flame 183 (2017) 372-385.

[58] M.J. Al Rashidi, M. Mehl, W.J. Pitz, S. Mohamed, S.M. Sarathy, Cyclopentane combustion chemistry. Part I: Mechanism development and computational kinetics, Combustion and Flame 183 (2017) 358-371. [59] M.J. Al Rashidi, S. Thion, C. Togbé, G. Dayma, M. Mehl, P. Dagaut, W.J. Pitz, J. Zádor, S.M. Sarathy, Elucidating reactivity regimes in cyclopentane oxidation: Jet stirred reactor experiments, computational chemistry, and kinetic modeling, Proceedings of the Combustion Institute 36 (2017) 469-477.

[60] M.J. McNenly, R.A. Whitesides, D.L. Flowers, Faster solvers for large kinetic mechanisms using adaptive preconditioners, Proceedings of the Combustion Institute 35 (2015) 581-587.

[61] H. Song, H. Song. Ignition delay measurements of iso-octane/ethanol blend fuel in a rapid compression machine. Proceedings of the European combustion meeting; 2015. p.

[62] G.E. Bogin Jr, J. Luecke, M.A. Ratcliff, E. Osecky, B.T. Zigler, Effects of iso-octane/ethanol blend ratios on the observance of negative temperature coefficient behavior within the Ignition Quality Tester, Fuel 186 (2016) 82-90.

[63] L. Cancino, M. Fikri, A. Oliveira, C. Schulz, Ignition delay times of ethanol-containing multicomponent gasoline surrogates: Shock-tube experiments and detailed modeling, Fuel 90 (2011) 12381244.

[64] D.M. Manias, E.A. Tingas, C.E. Frouzakis, K. Boulouchos, D.A. Goussis, The mechanism by which $\mathrm{CH} 2 \mathrm{O}$ and $\mathrm{H} 2 \mathrm{O} 2$ additives affect the autoignition of $\mathrm{CH} 4$ /air mixtures, Combustion and Flame 164 (2016) 111-125.

[65] M. Talei, E.R. Hawkes, Ignition in compositionally and thermally stratified n-heptane/air mixtures: A direct numerical simulation study, Proceedings of the Combustion Institute 35 (2015) 3027-3035.

[66] M.B. Luong, G.H. Yu, T. Lu, S.H. Chung, C.S. Yoo, Direct numerical simulations of ignition of a lean nheptane/air mixture with temperature and composition inhomogeneities relevant to $\mathrm{HCCl}$ and $\mathrm{SCCl}$ combustion, Combustion and Flame 162 (2015) 4566-4585. 
[67] M.B. Luong, R. Sankaran, G.H. Yu, S.H. Chung, C.S. Yoo, On the effect of injection timing on the ignition of lean PRF/air/EGR mixtures under direct dual fuel stratification conditions, Combustion and Flame 183 (2017) 309-321. 


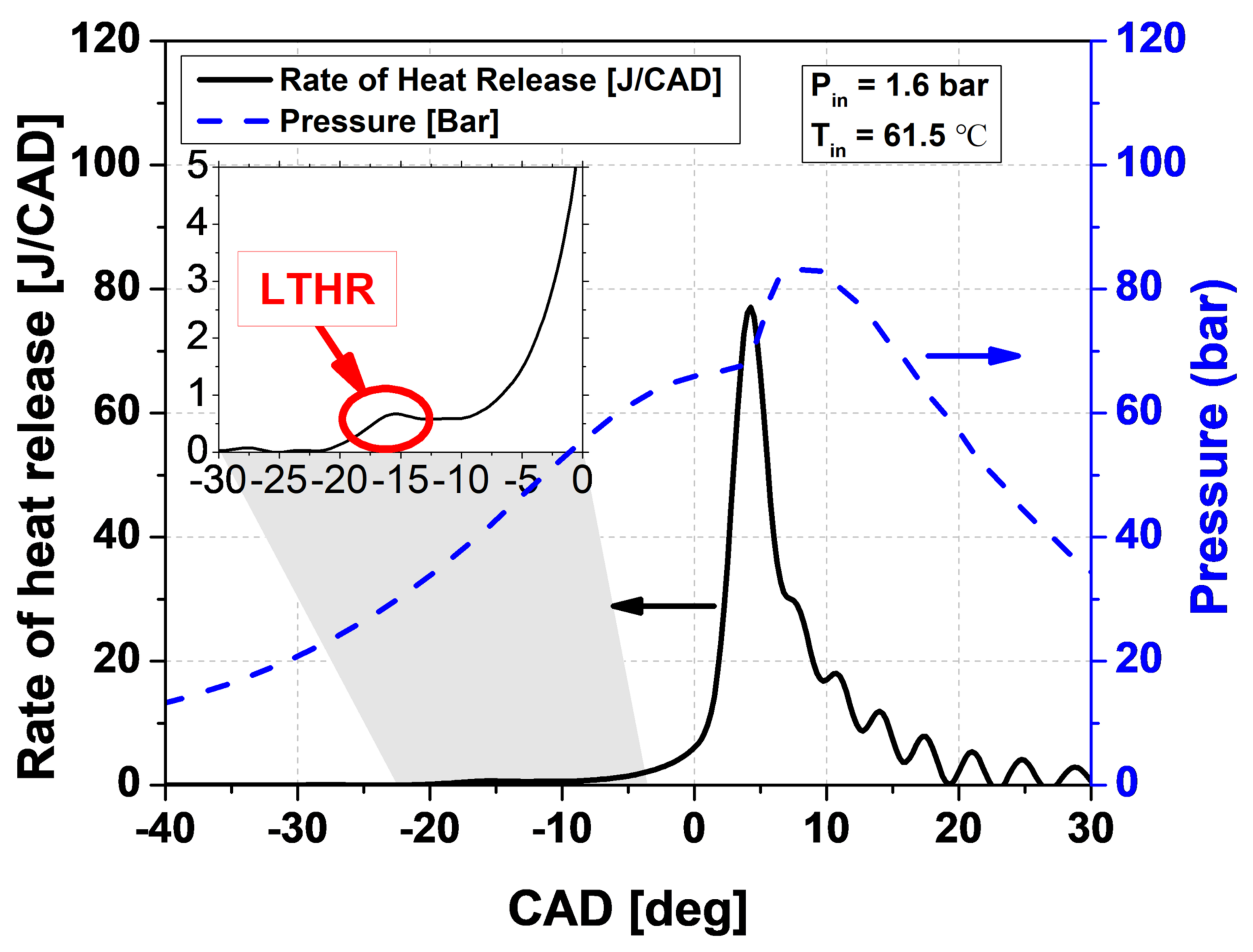




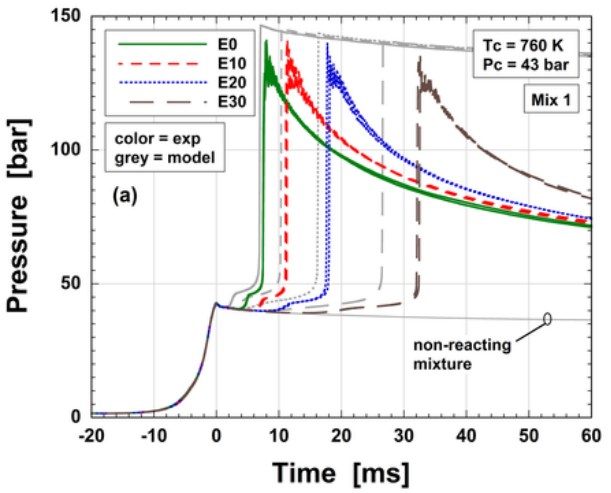




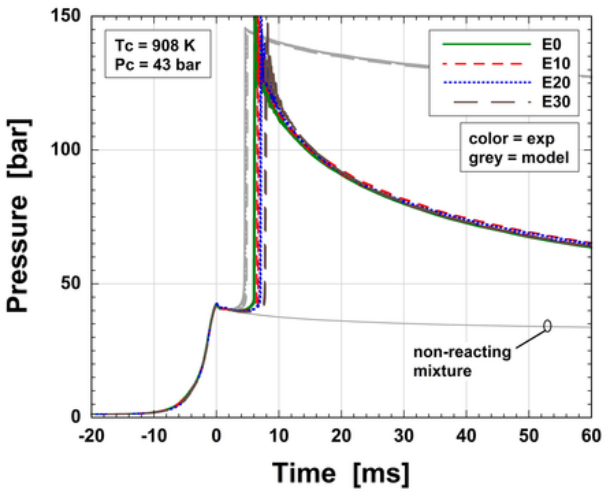




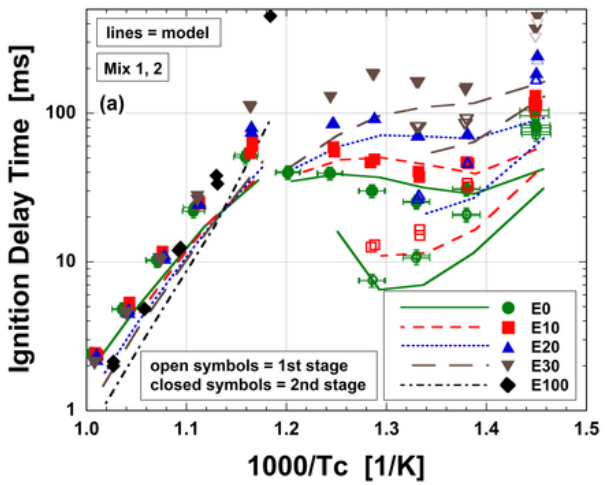




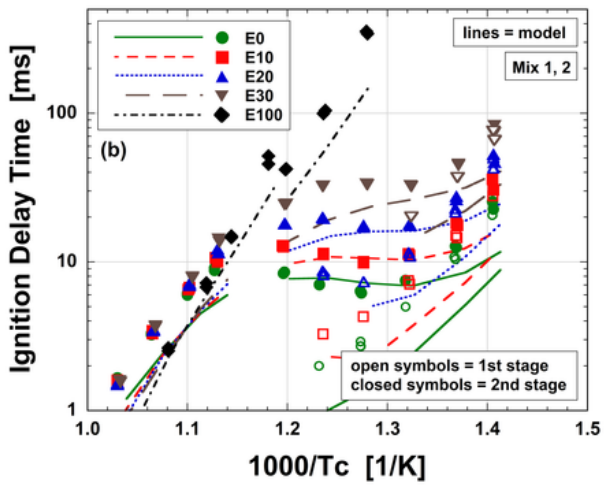




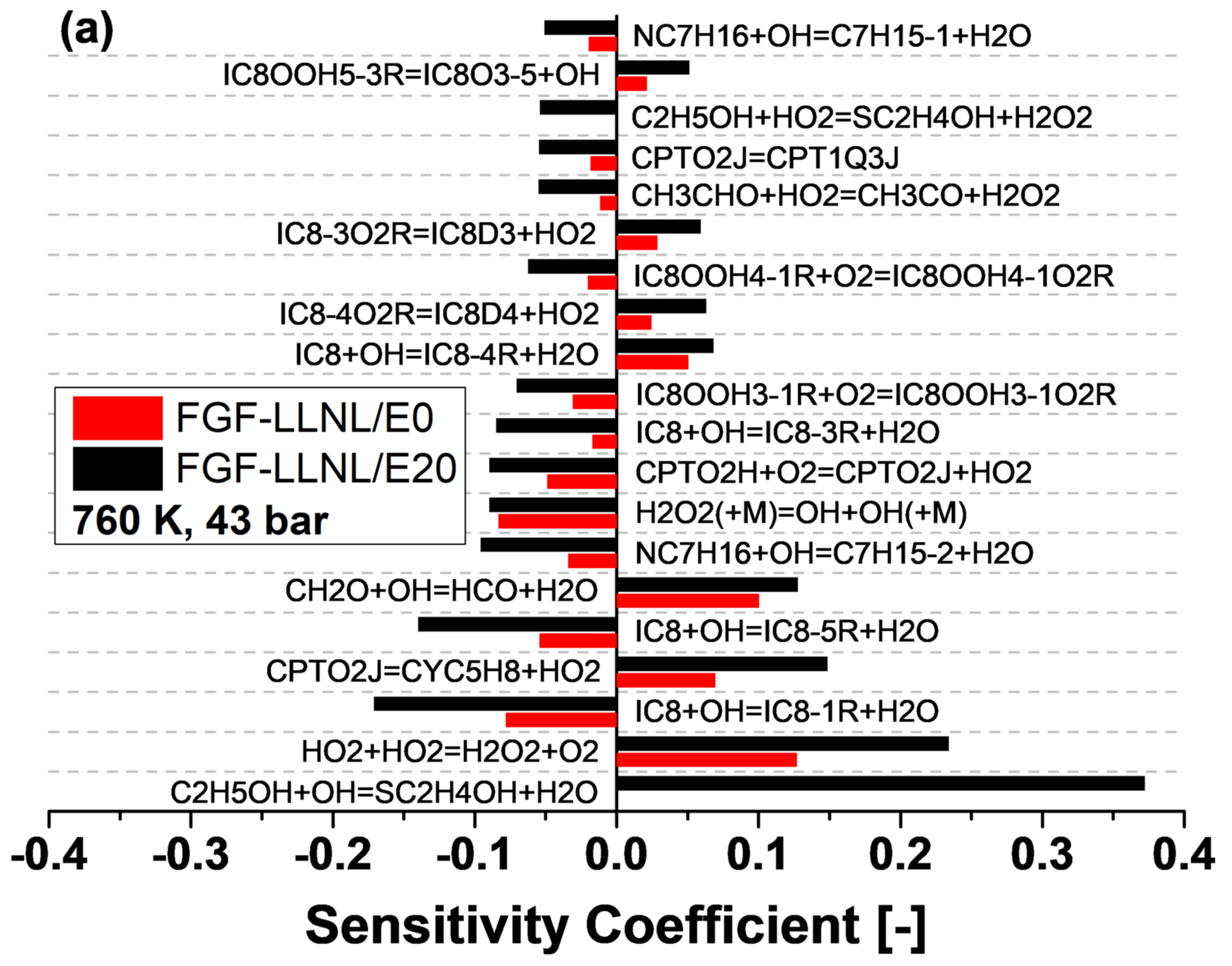




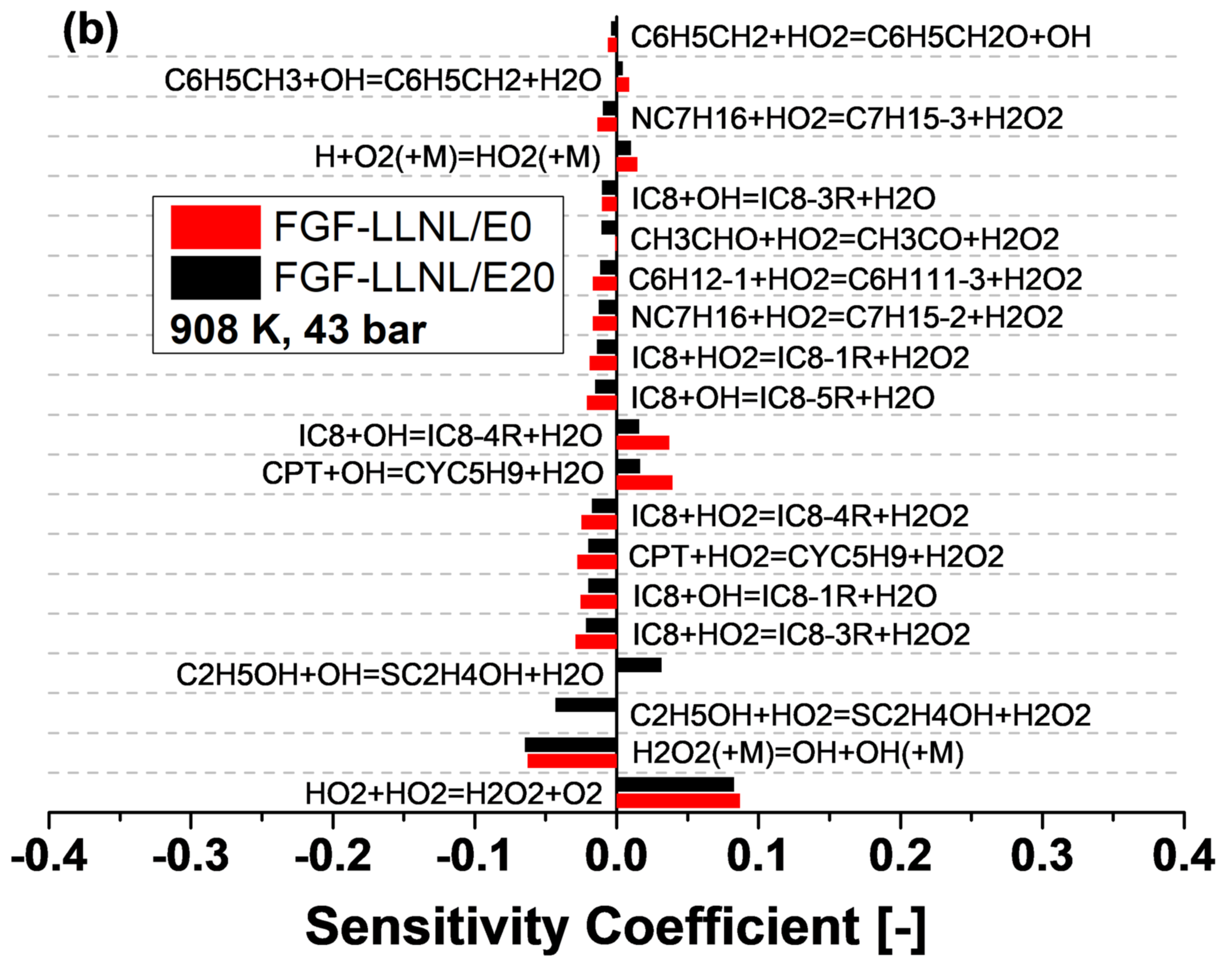




\section{FGF-LLNL/E0 FGF-LLNL/E20}

$760 \mathrm{~K}, 43$ bar

CPTO2J $=>$ CPT1Q3J

$\mathrm{NC} 7 \mathrm{H} 16+\mathrm{OH}<=>\mathrm{C} 7 \mathrm{H} 15-1+\mathrm{H} 2 \mathrm{O}$

IC8OOH4-1R + O2 <=> IC8OOH4-1O2R

IC8OOH3-1R + O2 <=> IC8OOH3-1O2R

$\mathrm{IC} 8+\mathrm{OH}<=>\mathrm{IC} 8-3 \mathrm{R}+\mathrm{H} 2 \mathrm{O}$

$\mathrm{NC} 7 \mathrm{H} 16+\mathrm{OH}<=>\mathrm{C} 7 \mathrm{H} 15-2+\mathrm{H} 2 \mathrm{O}$

$\mathrm{CH} 3 \mathrm{O} 2 \mathrm{H} \Leftrightarrow=\mathrm{CH} 3 \mathrm{O}+\mathrm{OH}$

$\mathrm{IC} 8+\mathrm{OH}<=>\mathrm{IC} 8-5 \mathrm{R}+\mathrm{H} 2 \mathrm{O}$

CPTO2H $+\mathrm{O} 2<=>$ CPTO2J $+\mathrm{HO} 2$

$\mathrm{IC} 8+\mathrm{OH} \Leftrightarrow=>\mathrm{IC} 8-1 \mathrm{R}+\mathrm{H} 2 \mathrm{O}$

$\mathrm{HO} 2+\mathrm{HO} 2<=>\mathrm{H} 2 \mathrm{O} 2+\mathrm{O} 2$

$\mathrm{IC} 80 \mathrm{OH} 5-3 \mathrm{R}<=>\mathrm{IC} 8 \mathrm{O} 3-5+\mathrm{OH}$

$\mathrm{IC} 8-3 \mathrm{O} 2 \mathrm{R}<=>\mathrm{IC} 8 \mathrm{D} 3+\mathrm{HO} 2$

$\mathrm{IC} 8+\mathrm{OH}<=>\mathrm{IC} 8-4 \mathrm{R}+\mathrm{H} 2 \mathrm{O}$

$\mathrm{CH} 2 \mathrm{O}+\mathrm{OH}<=\mathrm{HCO}+\mathrm{H} 2 \mathrm{O}$

- $\mathrm{CPTO2 \textrm {J }} \Leftrightarrow \mathrm{CYC} 5 \mathrm{H} 8+\mathrm{HO} 2$ $\mathrm{C} 2 \mathrm{H} 5 \mathrm{OH}+\mathrm{OH}<=>\mathrm{SC} 2 \mathrm{H} 4 \mathrm{OH}+\mathrm{H} 2 \mathrm{O}$

$\begin{array}{llllllllllllllll}-14 & -12 & -10 & -8 & -6 & -4 & -2 & 0 & 2 & 4 & 6 & 8 & 10 & 12 & 14\end{array}$ Sensitivity Coefficient [-] 
(a)

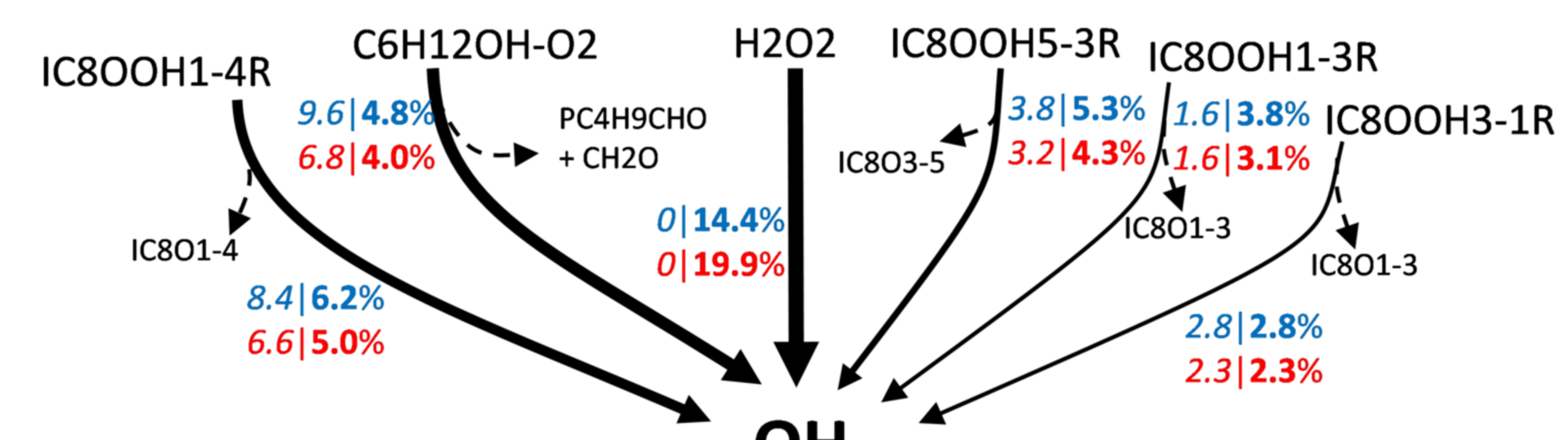

FGF-LLNL/EO

FGF-LLNL/E20

$760 \mid 908 \mathrm{~K}, 43 \mathrm{bar}$

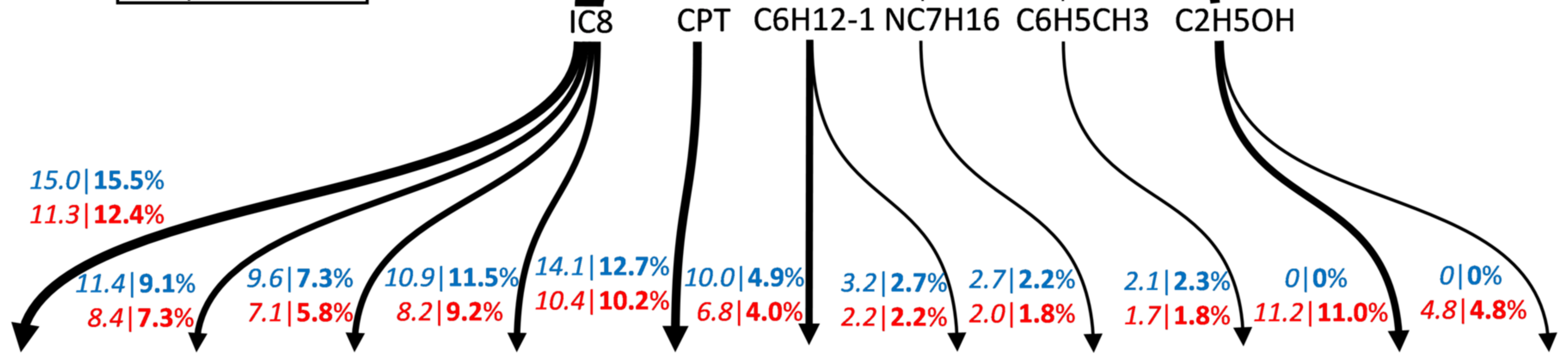


(b)

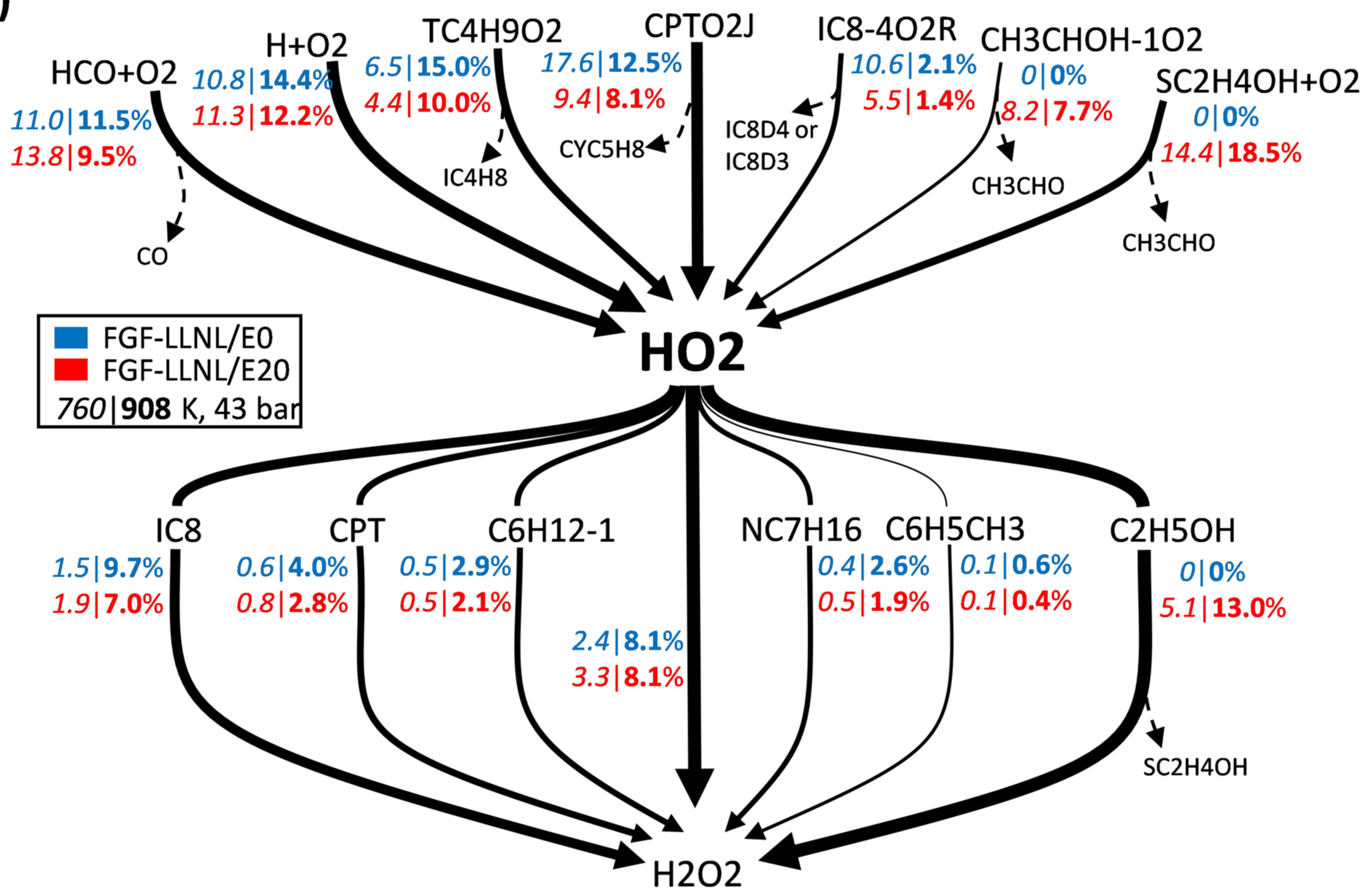




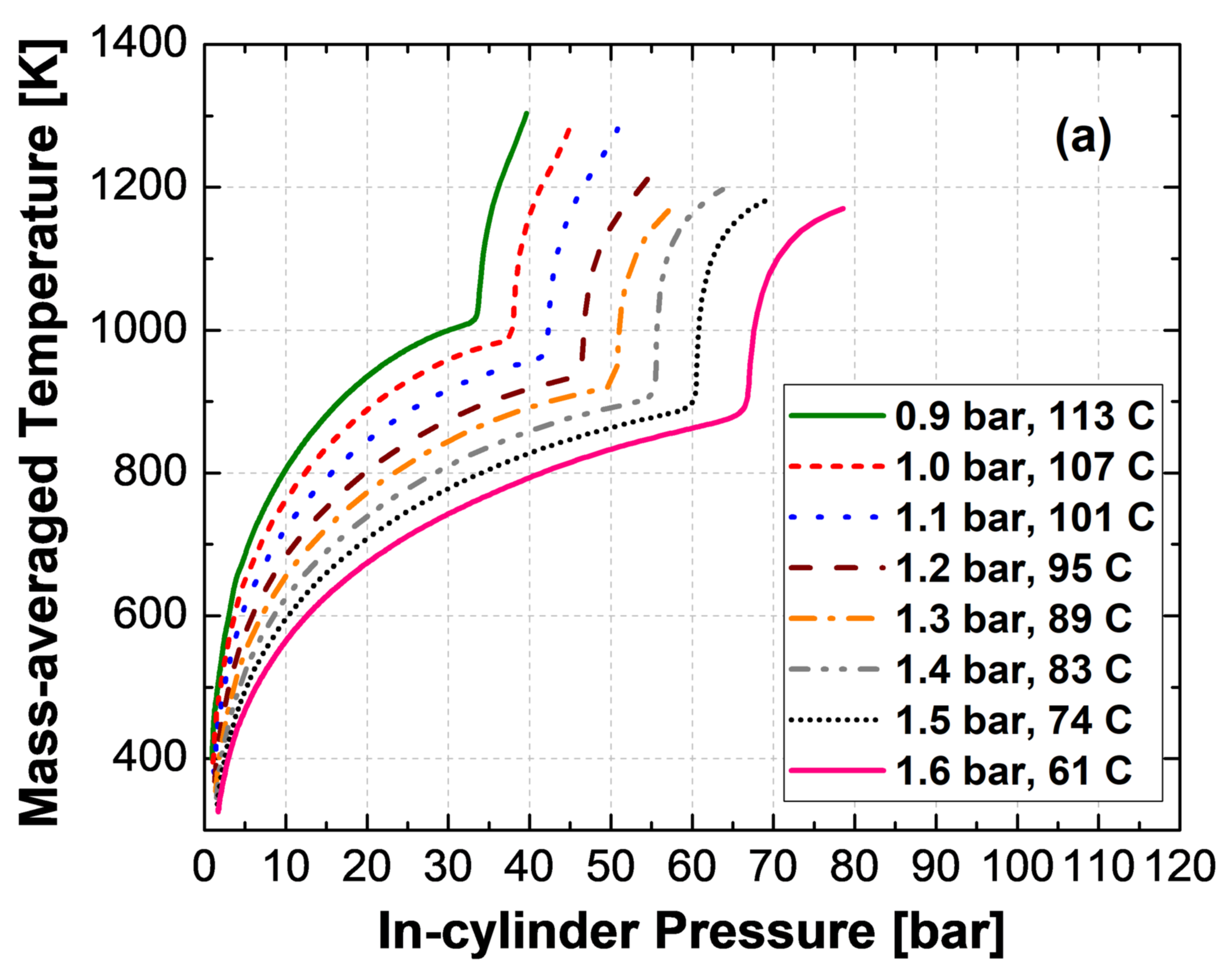




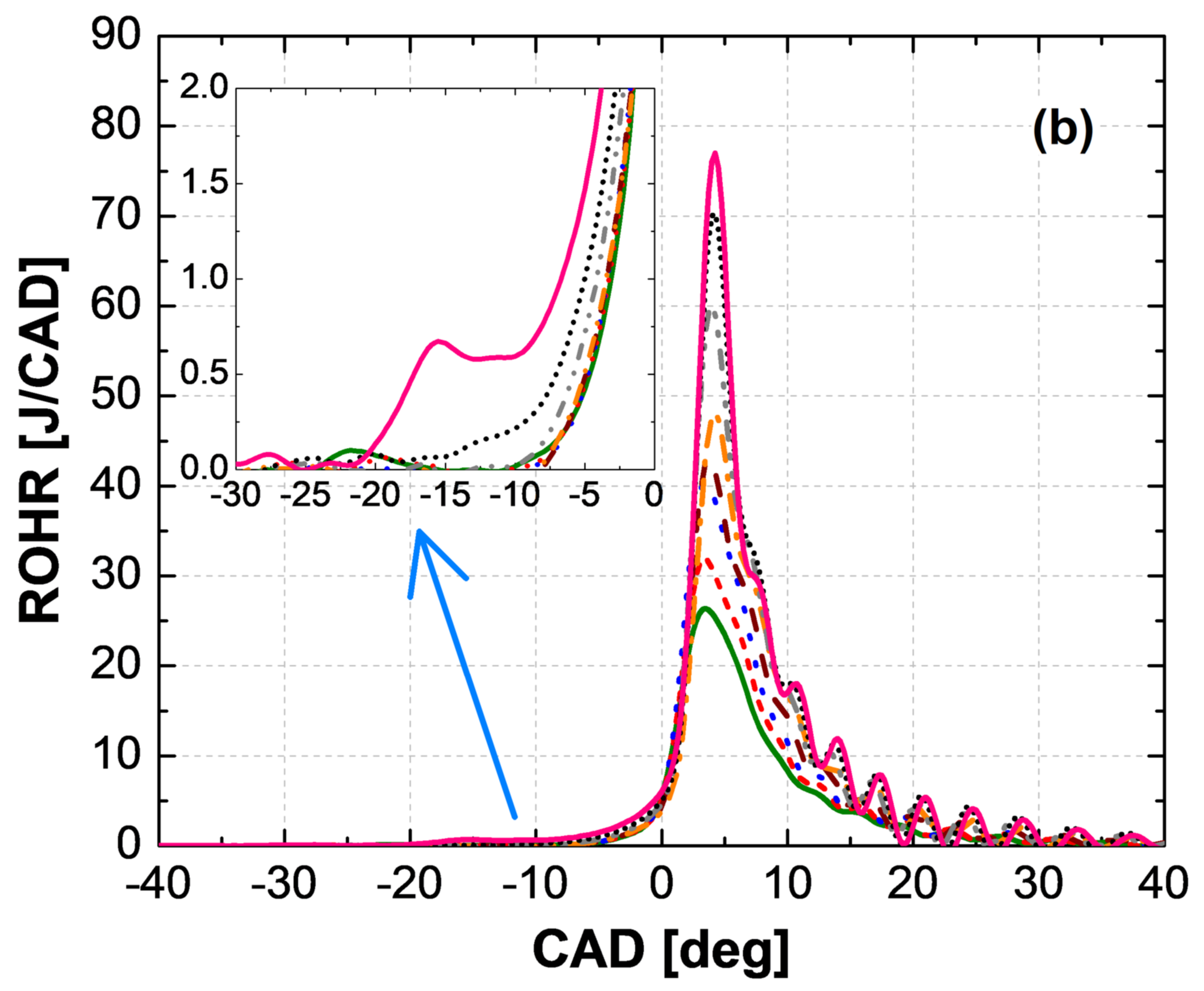




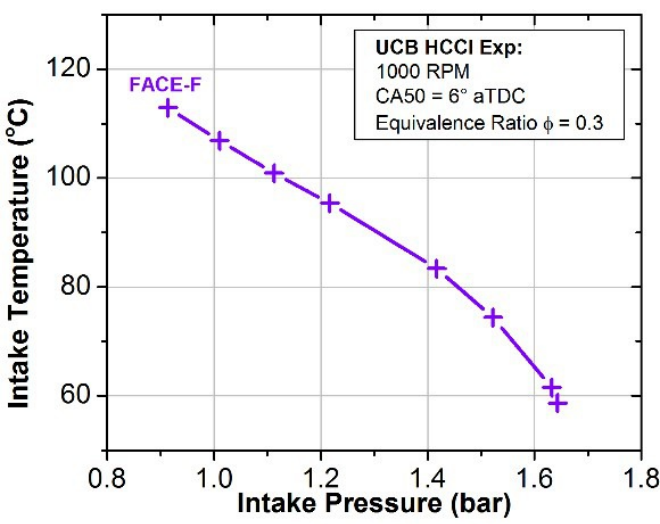




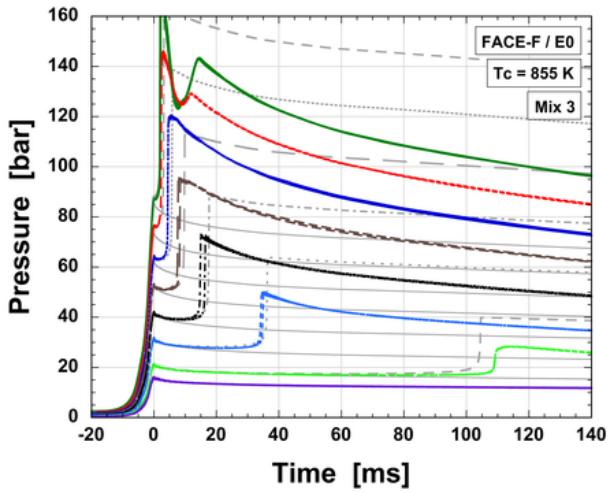




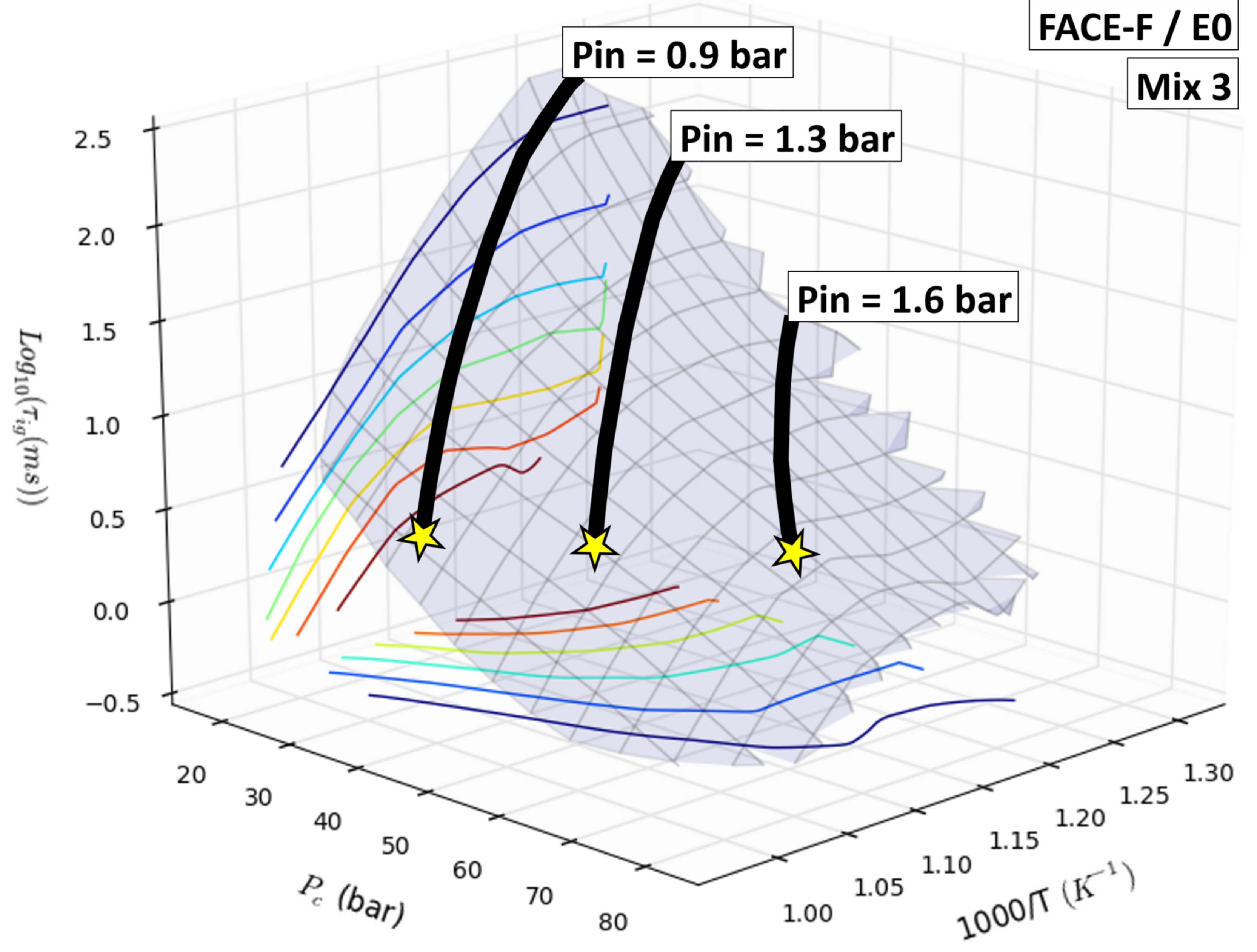




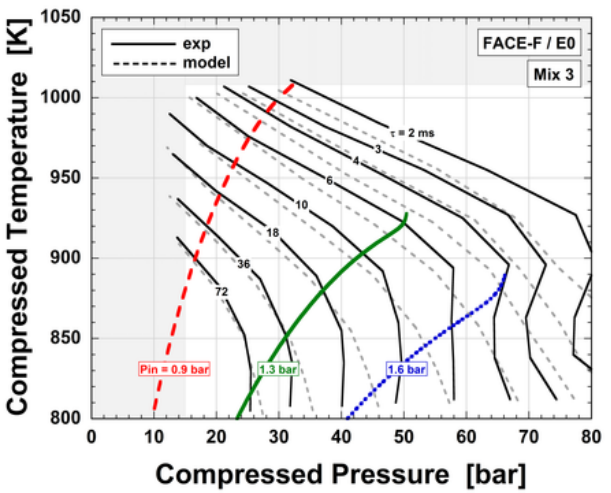




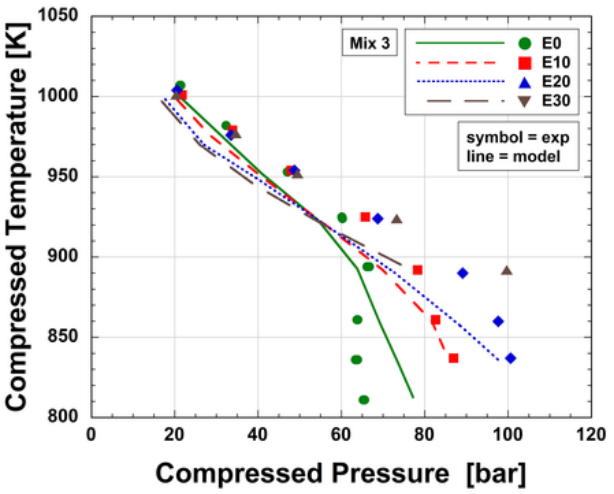

